\title{
Estudo comparativo entre PETG e PLA para Impressão 3D através de caracterização térmica, química e mecânica
}

\author{
A comparative study between PETG and \\ PLA for 3D Printing through thermal, \\ chemical and mechanical \\ characterization
}

\author{
Leonardo Santana ${ }^{1}$, Jorge Lino Alves ${ }^{2}$, \\ Aurélio da Costa Sabino Netto ${ }^{3}$, Claudia Merlini ${ }^{4}$
}

\footnotetext{
${ }^{1}$ Faculdade de Engenharia da Universidade do Porto (FEUP), Porto, Porto, Portugal.

${ }^{2}$ INEGI, Faculdade de Engenharia da Universidade do Porto (FEUP), Porto, Porto, Portugal.

${ }^{3}$ Instituto Federal de Santa Catarina (IFSC), Florianópolis, Santa Catarina, Brasil.

${ }^{4}$ Universidade Federal de Santa Catarina, Blumenau, Santa Catarina, Brasil.

e-mail: leonardosantana29@gmail.com,falves@fe.up.pt, asabino@ifsc.edu.br, claudia.merlini@ufsc.br
}

\begin{abstract}
RESUMO
A Impressão 3D baseada em extrusão se popularizou muito nos últimos anos devido ao surgimento de projetos de código aberto e máquinas de baixo custo, que tornaram a tecnologia acessível a todos os níveis de usuários. Paralelamente, novos materiais, em geral filamentos termoplásticos, são inseridos no mercado para aplicação neste tipo de técnica de fabricação, tornando cada vez mais necessário o desenvolvimento de estudos de caraterização experimentais dos materiais para fornecer dados técnicos aos utilizadores. Neste trabalho estudou-se o poli(tereftalato de etileno glicol) (PETG), polímero de recente adoção neste contexto, comparando-o ao poli(ácido lático) (PLA), o mais popular no âmbito da tecnologia. Ambos os materiais foram analisados mecanicamente à tração, através de amostras fabricadas por Impressão 3D variando os ângulos de deposição do material extrudado. Para a mesma análise, visando comparação, foram construídas peças por moldagem por injeção. Os materiais em seu estado inicial filamentar foram avaliados termicamente por TGA e DSC, e quimicamente por FTIR. As duas últimas técnicas de caracterização também foram aplicadas aos polímeros após o processamento por injeção e impressão. Os resultados obtidos mostraram que as propriedades mecânicas à tração dos componentes impressos são fortemente influenciadas pela orientação dos filamentos depositados nas camadas e pela mesoestrutura das peças. O PLA dispõe de superioridade mecânica, maior tensão máxima e elevada rigidez em relação ao PETG, nas amostras injetadas e impressas. O PETG, por sua vez, demostrou ser um material mais resistente à degradação térmica, mais estável termicamente (por não apresentar alterações significativas em seu comportamento térmico após ser processado), e flexível, propriedade esta que o torna muito interessante para aplicações na Impressão 3D. Por fim, a estrutura química molecular dos polímeros foi semelhante à descrita em outros estudos da literatura e pouco alterada pelos processos de fabricação.
\end{abstract}

Palavras-chave: Impressão 3D, moldagem por injeção, PETG, PLA, técnicas de caracterização.

\section{ABSTRACT}

The extrusion-based 3D printing has become popular in recent years due to the emergence of open source projects and low-cost machines that have made the technology accessible to all levels of users. In parallel, new materials, in general thermoplastic filaments, are inserted in the market for application in this type of manufacturing technique, making it increasingly necessary to develop experimental characterization studies to provide technical data to users. Thus, we sought to study poly(ethylene terephthalate glycol) (PETG), a polymer of recent adoption in this context, and compare it to poly(lactic acid) (PLA), the most popular one in 
this field. Both materials were mechanically analyzed by traction through samples made by 3D printing varying the angles of deposition of the extruded material. The same type of analysis was made using parts built by injection molding, for comparison purposes. The materials in their initial filamentary state were thermally evaluated by TGA and DSC, and chemically evaluated by FTIR. The last two characterization techniques were also applied to the polymers after the injection and 3D printing processing. The results showed that the tensile mechanical properties of the printed components are strongly influenced by the orientation of the filaments deposited in the layers and by the mesostructure of the parts. PLA has mechanical superiority, greater maximum tension and high rigidity, in relation to PETG, in the injected and printed samples. PETG, in turn, has shown to be more resistant to thermal degradation, more thermally stable (because it does not show significant changes in its thermal behavior after being processed), and more flexible, which is very interesting for 3D printing applications. Finally, the molecular chemical structure of both polymers was similar to that described in other studies found in the literature and was slightly altered by the manufacturing processes.

Keywords: 3D Printing, injection molding, PLA, PETG, characterization techniques.

\section{INTRODUÇÃO}

A Impressão 3D pode ser definida como um processo utilizado para fabricar objetos tridimensionais baseado em uma deposição, controlada digitalmente, de sucessivas camadas de material até a criação de uma estrutura final. Também conhecida como Manufatura Aditiva, a tecnologia se opõe aos princípios da manufatura subtrativa, em que componentes são construídos através da remoção de material por processos como furação, fresamento, corte por serragem, entre outros [1-3]. Entre as principais vantagens da Impressão 3D em comparação aos processos de fabricação tradicionais estão: (i) eficiência: produção rápida e econômica, com baixas quantidades de material residual; (ii) criatividade: ideal para confecção de geometrias complexas; (iii) acessibilidade: preço razoável de máquinas e materiais [4].

No âmbito da Impressão 3D, a Modelagem por Fusão e Deposição (FDM) caracteriza-se por uma das técnicas mais comuns, devido principalmente à sua facilidade de uso e boa relação de custo benefício [5]. O processo FDM consiste em tecnologia baseada em extrusão, na qual a matéria prima utilizada, em sua forma inicial, é um filamento, que é gradualmente aquecido e extrudado por um bico calibrado sobre uma plataforma de construção. O material depositado rapidamente resfria, solidifica, e se une às estruturas previamente extrudadas. Ao final da construção de uma camada completa, a plataforma desloca-se para baixo de modo a acomodar a próxima camada de material. Este processo é repetido até fabricação final da peça [6,7].

Após a expiração das patentes relativas ao FDM, desenvolveu-se uma grande comunidade voltada à elaboração de sistemas de código aberto, o que proporcionou o surgimento de equipamentos comerciais e máquinas do tipo "faça você mesmo" (Do It Yourself - DIY) baseadas nesta tecnologia. Como resultado, em poucos anos os preços das máquinas foram reduzidos em cerca de duas ordens de grandeza [8]. Dentre os equipamentos de baixo custo, destacam-se as impressoras 3D desktop RepRap, Makerbot, Cube, entre outras, que tornaram a tecnologia acessível para o uso doméstico e em escritórios [9]. Os principais materiais utilizados nesta categoria de máquinas são os filamentos termoplásticos de Acrilonitrila Butadieno Estireno (ABS), Poli (ácido lático) (PLA), Politereftalato de Etileno Glicol (PETG), Policarbonato (PC) e Nylon [10].

Entre os entusiastas da Impressão 3D, as chamadas comunidades "makers", o PLA caracteriza-se por ser um dos materiais mais populares, disponibilizado em várias cores e pela maioria dos fornecedores de suprimentos para a tecnologia, além de apresentar maior facilidade para imprimir quando comparado, por exemplo, ao ABS [11,12]. O PLA dispõe de melhores características termomecânicas que o ABS, apresentando maior resistência mecânica e menor coeficiente de expansão térmica, o que melhora sua capacidade de impressão, reduzindo efeitos como o empenamento durante o processo de fabricação [9].

O poli(ácido lático) consiste em um poliéster alifático linear, termoplástico, semicristalino ou amorfo. Trata-se de um polímero sintetizado a partir de fontes renováveis como o açúcar de milho, batata, e cana de açúcar, através de biconversão e polimerização. O PLA dispõe de características interessantes, tais como biocompatibilidade, biodegradabilidade, e absorção biológica, além de boas propriedades mecânicas e de processabilidade, estabilidade térmica e baixo impacto ambiental [13-17]. A resistência à tração do PLA encontra-se em aproximadamente (50 a 70) MPa e o módulo de elasticidade entre (3,0 e 4,0) GPa, dependendo da massa molar e da composição estereoquímica [18,19]. Termicamente o PLA apresenta uma temperatura de transição vítrea próxima a $(55$ a 65$){ }^{\circ} \mathrm{C}$ [20], e quando semicristalino um ponto de fusão no intervalo de (170 a 180) ${ }^{\circ} \mathrm{C}$ [21]. O material é utilizado em muitas indústrias, sobretudo em setores como a fabricação de implantes médicos biodegradáveis e embalagens para alimentos [22]. Entretanto, algumas deficiências do PLA, como a fragilidade inerente, um limitado alongamento até a ruptura, e uma baixa resistência ao impacto, 
constituem alguns desafios para a ampla aplicação do material [18, 23, 24].

Atualmente um material que vem ganhando espaço entre os usuários da comunidade de impressão 3D e produtores de filamentos é o já mencionado PETG, principalmente quando se há a necessidade de construir peças flexíveis e duráveis. Neste cenário, é anunciado como um filamento que reúne as melhores qualidades do ABS (resistente e dúctil) com a facilidade de impressão que o PLA oferece. Caracteriza-se por ser uma versão modificada do PET, na qual o "G" significa "glicol modificado", sendo adicionado à composição do material durante a polimerização. O resultado deste processo é um filamento mais transparente, menos rígido, e mais fácil de ser utilizado do que a sua forma base, o PET. O PETG, quimicamente descrito como poly(ethylene terephthalate-co-1, 4-cylclohexylenedimethylene terephthalate), é um polímero amorfo, o qual mantém seu estado semissólido quando aquecido, o que o torna adequado para a Impressão 3D. É aplicado na produção de garrafas de água, embalagens de alimento, entre outros itens de plástico [25-27].

Em um aspecto geral, o PETG consiste em um polímero com temperatura de transição vítrea próxima a $80^{\circ} \mathrm{C}$, com propriedades mecânicas semelhantes às do PET, tendo como vantagens uma notável tenacidade, flexibilidade, e alta capacidade de processamento [28]. Estudos como os de LAM et al. [29] encontraram valores de resistências à tração, alongamento até a ruptura e módulo de elasticidade para o PETG próximos a $25 \mathrm{MPa}, 93 \%$, e 1,6 GPa, respectivamente. Já no trabalho de FOCKE et al. [30], para as mesmas propriedades, os resultados foram, seguindo a ordem, 50,4 MPa, 73\%, e 2,02 GPa.

Devido à natureza dos projetos de código aberto, de acordo com ALBUQUERQUE [31] não existe uma autoridade que regularize, padronize e estabeleça especificações a respeito das características técnicas que os filamentos utilizados na Impressão 3D devem apresentar. Por isso, segundo o mesmo, dependendo do material, cor, ou fornecedor do filamento, os parâmetros utilizados no processo podem ser diferentes, o que leva, na maior parte dos casos, os usuários a ajustar as configurações através do método de tentativa e erro. Muitas vezes os materiais não possuem folhas técnicas (data-sheets), ou em alguns casos fabricantes de impressoras 3D publicam dados sobre os materiais utilizados em suas máquinas, mas são informações incompletas [32,33].

No sentindo de caracterizar as propriedades dos filamentos e das peças geradas por estes, com relação ao PLA a situação encontra-se mais explorada. Recentemente, estudos como os de SANTANA et al. [34], CUIFFO et al. [35], SONG et al. [36], PAGE et al. [37], WANG et al. [38] e SABINO NETTO et al. [39] buscaram avaliar as propriedades químicas, térmicas e mecânicas do material, os quatro últimos comparando o comportamento mecânico de componentes impressos com elementos fabricados pela moldagem por injeção.

Especialmente sobre o PETG, justamente por ser um material de recente adoção na Impressão 3D, poucos estudos foram realizados para explorar as propriedades anteriormente citadas. Algumas iniciativas, como os trabalhos de SZYKIEDANS et al. [32], SZYKIEDANS e CREDO [33], e TANIKELLA et al. [11], avaliaram as propriedades mecânicas à tração de peças impressas em PETG, entretanto são superficiais e pouco exploraram este comportamento mediante o uso de diferentes estratégias de construção das amostras pelo processo. Diante do exposto, verificou-se a necessidade de realização de um estudo com este material, buscando caracterizar suas propriedades mecânicas através da fabricação de amostras construídas com diferentes configurações de impressão, e sem as influências do processo, isto é, com componentes fabricados por moldagem por injeção (aproximar o máximo possível as propriedades "puras" do material), além de obter as características químicas e térmicas do material em seu estado filamentar e após o processamento pelas tecnologias de fabricação citadas. Como trata-se um material comercializado com a proposta de boa capacidade de impressão, assim como o PLA, neste estudo buscou-se realizar uma comparação com este último, pelas mesmas técnicas descritas anteriormente, e assim fornecer aos usuários uma ficha técnica dos materiais experimentalmente obtida e fundamentos para a seleção dos materiais para a impressão de peças, modelos (protótipos) ou funcionais.

\section{MATERIAIS E MÉTODOS}

Neste trabalho foram avaliados dois filamentos poliméricos de $1,75 \mathrm{~mm}$ de diâmetro, utilizados para impressão 3D: PLA da empresa 3D INK (cor azul) e PETG (transparente) do fornecedor RepRap.pt - Figura 1 (a). Os materiais foram caracterizados em três condições: na sua forma inicial (filamentar), e após ser processado por tecnologias de moldagem por injeção e de Manufatura Aditiva por extrusão - representadas respectivamente na Figura 1 (b), (c) e (d). Experimentalmente este trabalho foi divido em dois grupos de análise, conforme mostrado na Figura 2. 


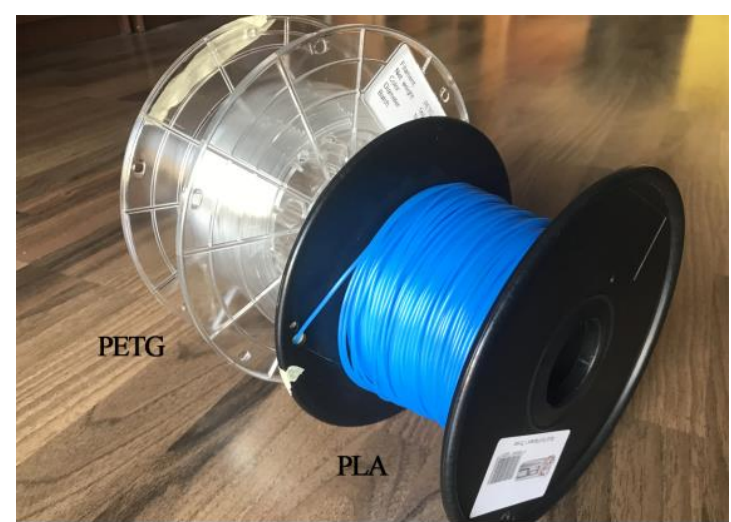

(a)

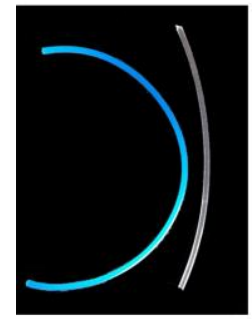

(b)

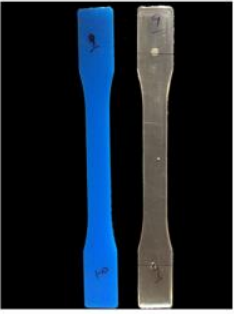

(c)

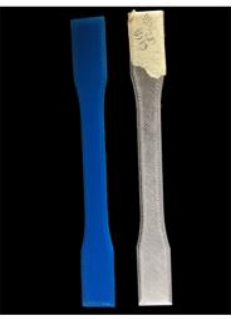

(d)

Figura 1: Bobinas de filamento (forma comercializada) (a), amostras de filamento (b), peças fabricadas por injeção (c) e impressão 3D (d).

\section{Filamentos (forma inicial)}

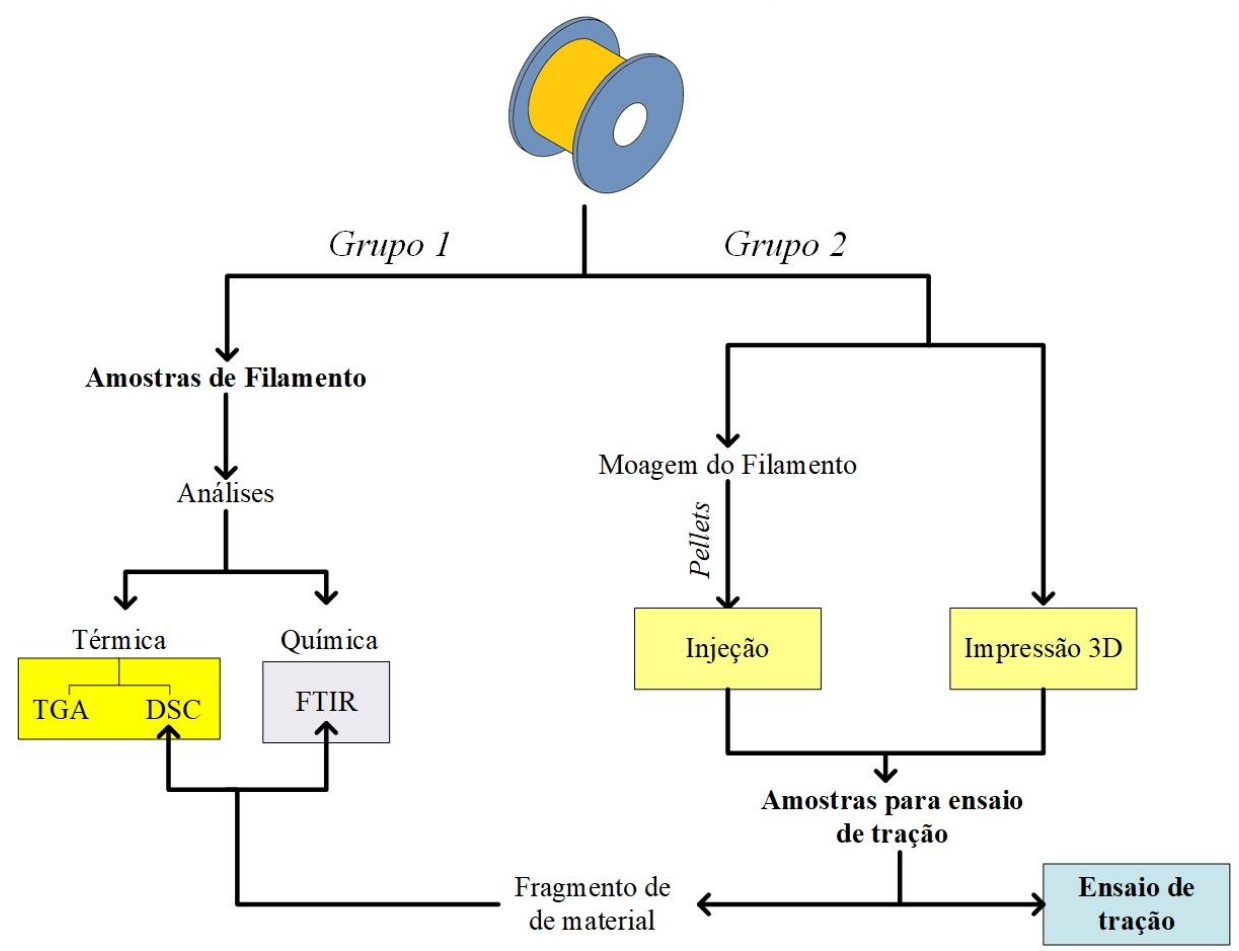

Figura 2: Metodologia de análise. 


\subsection{Grupo 1: análises térmicas e químicas}

Primeiramente os filamentos foram analisados térmica e quimicamente. O comportamento térmico dos termoplásticos foi estudado aplicando-se técnicas de análise termogravimétrica (TGA) e calorimetria diferencial de varredura (DSC). A primeira foi utilizada para obter as temperaturas de degradação de ambos os polímeros, PLA e PETG. Com a análise de DSC buscou-se identificar as temperaturas de transição vítrea $\left(T_{g}\right)$, fusão $\left(T_{m}\right)$ e cristalização $\left(T_{c}\right)$, além de se obter o grau de cristalinidade ${ }^{1}$ do material $\left(X_{c}\right)$ (equação (1) [40]) — as três últimas características para o caso de um polímero semicristalino.

$$
X_{c}=\frac{\Delta H_{f}}{\Delta H_{f}^{0} \cdot \phi_{m}} \cdot 100
$$

Utilizou-se a técnica da espectroscopia no infravermelho por transformada de Fourier (FTIR) para verificar as principais moléculas que compõem a estrutura dos filamentos e comparar os resultados com materiais semelhantes analisados na literatura. As condições para todos os ensaios, igualmente utilizadas para os dois materiais, bem como os equipamentos de análise, são apresentados na Tabela 1.

Em um segundo momento as análises térmicas, especialmente ${ }^{2}$ o DSC, e químicas foram realizadas em amostras de ambos os materiais, coletadas dos corpos de prova de tração fabricados por injeção (a partir dos filamentos peletizados) e Impressão 3D. Foi analisada uma amostra de material para cada condição, injetada e impressa, em cada uma das técnicas de caracterização citadas. Especificamente nas peças impressas, o fragmento de material para os estudos mencionados foi retirado das peças (PLA e PETG) que apresentaram os melhores resultados para tensão máxima e módulo de Young. O objetivo destes experimentos foi verificar se ocorreram diferenças significativas na estrutura molecular e nas características térmicas dos polímeros em função das variáveis (fatores de influência) dos processos de fabricação aos quais foram aplicados. As condições para os ensaios foram as mesmas utilizadas nas análises dos filamentos (Tabela 1).

Tabela 1: Condições dos ensaios térmicos e químico.

\begin{tabular}{l|l|l}
\hline ENSAIO & CONDIÇÕES & EQUIPAMENTOS \\
\hline TGA & $\begin{array}{l}\text { Taxa de aquecimento de } 20^{\circ} \mathrm{C} / \mathrm{min}, \text { intervalo } \\
\text { entre } 25^{\circ} \mathrm{C} \text { e } 800^{\circ} \mathrm{C}, \text { atmosfera de ar sintético }\end{array}$ & SDT Q600 TA Instruments \\
\hline DSC & $\begin{array}{l}\text { Rampa de aquecimento de } 0^{\circ} \mathrm{C} \text { a } 250^{\circ} \mathrm{C}, \text { taxa } \\
\text { de } 10^{\circ} \mathrm{C} / \mathrm{min}, \text { atmosfera de nitrogênio. }\end{array}$ & Q20 TA Instruments \\
\hline FTIR & Espectros entre $(4000$ e 600$) \mathrm{cm}-1$ & Cary 630 FTIR, Agilent Technologies \\
\hline
\end{tabular}

\subsection{Grupo 2: análises mecânicas}

Peças fabricadas pelo processo de Impressão 3D por extrusão apresentam uma mesoestrutura formada por uma densidade de vazios e pela existência de ligações "filamento a filamento depositado", dentro e entre as camadas, Figura 3. A mesoestrutura, por sua vez, é determinada pelas trajetórias de deposição dos filamentos e pelos parâmetros de processo. A presença de vazios no interior das peças se dá pela forma oblonga dos filamentos que as constituem. O tamanho e a forma dos vazios, bem como a extensão da união entre filamentos individuais (área de contato), são fatores que influenciam na anisotropia e na magnitude da resistência mecânica desenvolvida pelas peças [43-45].

\footnotetext{
${ }^{1} \boldsymbol{\Delta} H_{f}$ corresponde `a entalpia de fusão da amostra em (J/g), obtida experimentalmente e apresentada na Tabela $4 ; \boldsymbol{\phi} \mathrm{m}$ foi considerado 1 por se tratar de polímero puro; $\Delta H_{f}^{0}$ é a entalpia de fusão do PLA hipoteticamente $100 \%$ cristalino, neste caso igual $93 \mathrm{~J} / \mathrm{g}$ [41, 42]

${ }^{2}$ É importante destacar que as mesmas respostas avaliadas na análise de DSC com os filamentos em sua condição inicial foram investigadas nos fragmentos de peça impressa e injetada.
} 

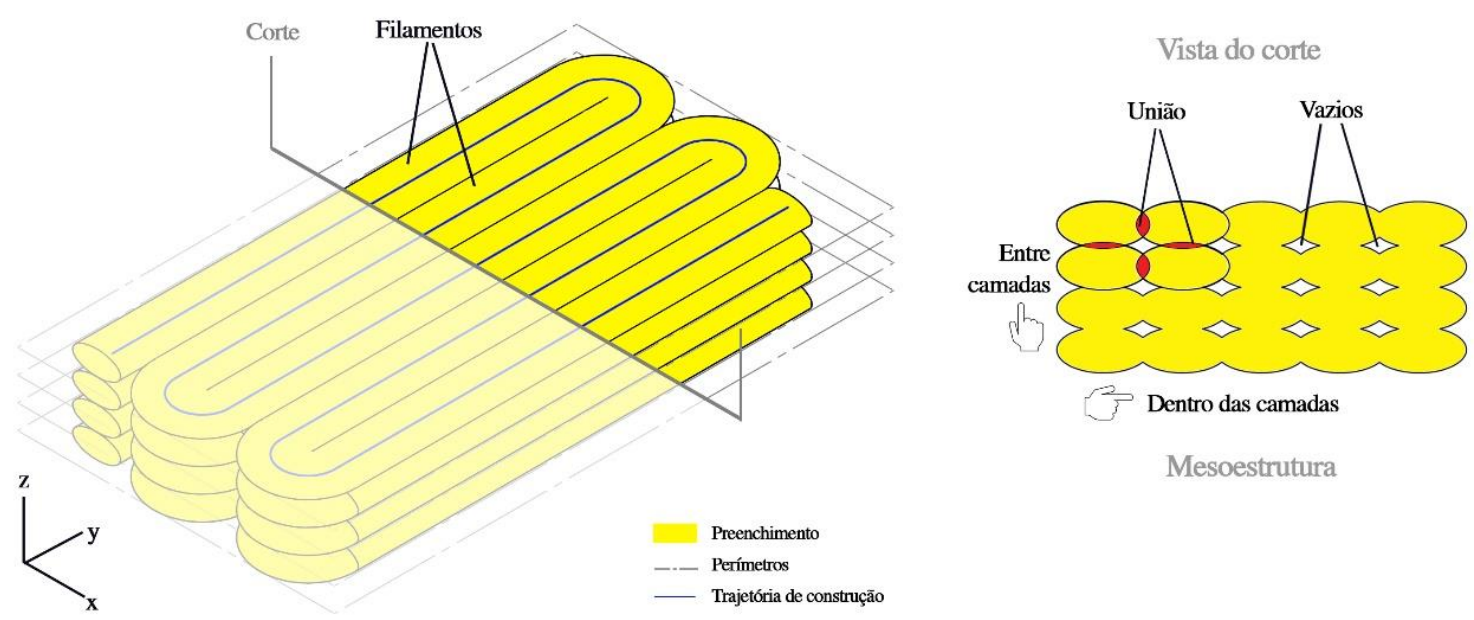

Figura 3: Representação da mesoestrutura das peças fabricadas pelo processo de Impressão 3D por extrusão.

Com base no conceito descrito e na importância dos parâmetros de processo na construção e determinação das propriedades estruturais (e consequentemente mecânicas) das peças impressas, foram fabricados neste estudo corpos de prova para ensaio de tração, com geometrias baseadas na norma ASTM D638 [46] Tipo 1, em PLA e PETG, com diferentes configurações paramétricas. Para um melhor entendimento sobre como as amostras foram construídas, alguns conceitos sobre parâmetros de processo — Figura 4 (a) e (b) — precisam ser descritos [47-52]:

(a)

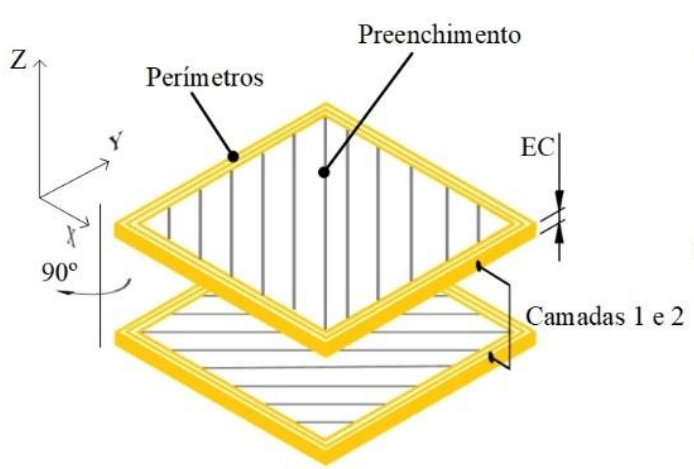

Representação 2D das camadas
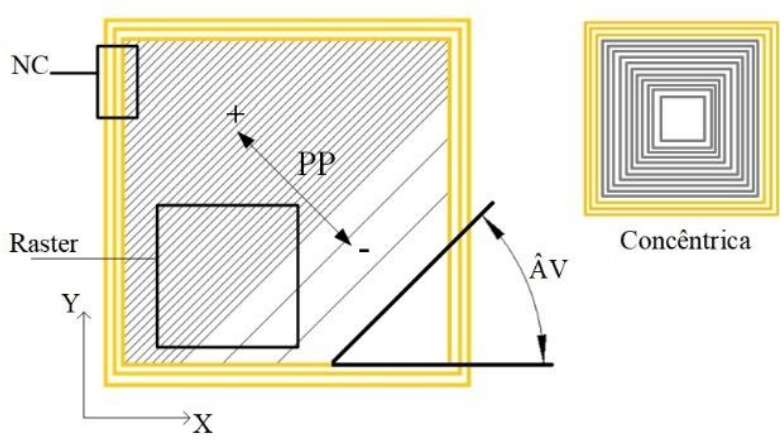

Concêntrica

(b)

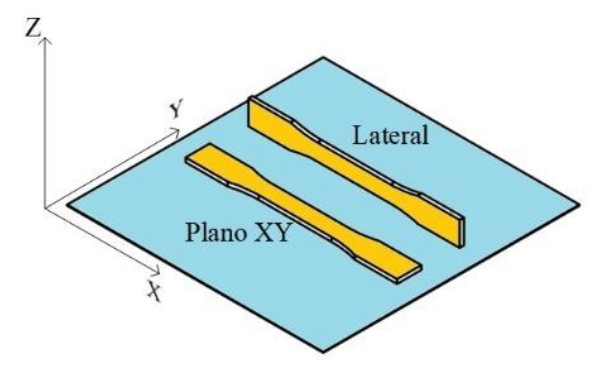

Plataforma de construção

Figura 4: Representação das camadas e dos parâmetros (a) e (b) orientação de construção.

a) espessura de camada (EC): corresponde à espessura de cada camada depositada, e o seu valor depende do diâmetro do bico de extrusão. Geralmente é ajustada em um valor menor que $80 \%$ do diâmetro do bico; 
b) ângulo de varredura (ÂV): é a direção em que os filamentos depositados se encontram em relação ao eixo $\mathrm{X}$ da plataforma de construção;

c) orientação de construção (OC): é a orientação da peça na plataforma de construção em relação aos seus eixos $\mathrm{X}, \mathrm{Y}$ e Z $\mathrm{X}$. e Y são os eixos paralelos à plataforma, e $\mathrm{Z}$ é a direção de construção das peças;

d) estratégia de preenchimento (EP): a construção de cada camada tem início com a determinação do perímetro da seção transversal da peça fabricada. Após concluir o perímetro, o preenchimento interno da peça é feito. Este preenchimento tradicionalmente é baseado em três padrões: raster (filamentos depositados em zig-zag); contorno/concêntrico (reprodução do perímetro ou perfil da peça); ou a combinação dos dois;

e) percentual de preenchimento (PP): define a quantidade de material no interior da peça;

f) número de contornos (NC): corresponde ao número de perímetros, internos e externos, construídos em torno das peças.

Descritos os parâmetros de processo, as amostras impressas neste trabalho foram confeccionadas com diferentes ângulos de varredura (ÂV), estratégias de deposição (ED), e orientações de construção (OC). A combinação dos parâmetros citados e dos níveis atribuídos a estes geraram três configurações, conforme mostrado na Tabela 2. Para cada configuração foram construídas cinco amostras, em uma impressora 3D modelo Prusa I3 Hephestos $(B Q)$ (diâmetro do bico extrusor = 0,4 mm), configurando um total de 15 peças por material.

Tabela 2: Combinações paramétricas para a fabricação das amostras.

\begin{tabular}{l|l|l|l}
\hline \multirow{2}{*}{ CONDIÇÃo } & \multicolumn{1}{|c|}{ CONFIGURAÇÃO PRINCIPAL } & \multicolumn{1}{|c}{ PARÂMETROS AUXILIARES } \\
\cline { 2 - 4 } & \multicolumn{1}{|c}{ ÂV(ํ) } & \multicolumn{1}{|c}{ ED (u.a) } & \multicolumn{1}{c}{ OC (u.a) } \\
\hline $\mathrm{C} 1$ & $45 /-45$ & Raster & Plano XY \\
\hline $\mathrm{C} 2$ & $0 / 90$ & Raster & Plano XY \\
\hline $\mathrm{C} 3$ & Unidirecional $\left(0^{\circ}\right)$ & Concêntrica & Lateral \\
\hline
\end{tabular}

É importante destacar que um dos intuitos da análise mecânica, além de comparar os dois materiais, foi avaliar a influência dos ângulos de deposição dos filamentos dentro das camadas ( $\hat{A} \mathrm{~V}$ ) na qualidade das peças. No entanto, o uso de diferentes estratégias e orientações de construção ${ }^{3}$, Tabela 2 , foi necessário para que se pudesse obter diferentes configurações de ângulos de varredura, e principalmente para a fabricação de peças com a maior quantidade de filamentos possível, depositados unidirecionalmente, por área de cada camada e entre as camadas. Por padrão, o software de fatiamento utilizado para o planejamento de construção das peças, o Slic $3 r$ inverte as camadas em $90^{\circ}$ durante a impressão dos modelos — Figura 4 (a). Em outras palavras, quando o usuário ajusta o ângulo de varredura em $0^{\circ}$, por exemplo, o modelo será confeccionado com camadas com preenchimento interno em $0^{\circ}$ alternando com camadas com preenchimento em $90^{\circ}$.

Para serem obtidas as amostras com a configuração unidirecional, com todos filamentos alinhados na direção de aplicação da carga de tração, desenvolveu-se uma solução que combinou o uso de uma estratégia de deposição concêntrica - Figura 4 (a) —, que consiste na reprodução da geometria do modelo ao longo de todo o preenchimento da camada, com uma orientação de construção lateral da peça — Figura 4 (b). Importantes parâmetros do processo de Impressão 3D foram mantidos fixos na construção dos corpos de prova: espessura de camada (EC) $(0,2 \mathrm{~mm})$, número de perímetros (NP) (3 perímetros) e o percentual de preenchimento (PP) (100\%) - Figura 4 (a). Especificamente sobre o valor de PP, buscou-se construir peças o mais próximo possível de um componente sólido; entretanto, mesmo com este valor máximo, vazios naturais do processo inevitavelmente estiveram presentes no interior das amostras - Figura 3. Além desses parâmetros, ressaltam-se as temperaturas de processamento (extrusão) dos materiais, $215^{\circ} \mathrm{C}$ para o PLA e $235^{\circ} \mathrm{C}$ para o PETG, e da plataforma de construção, $70^{\circ} \mathrm{C}$ para ambos. Quanto aos ensaios de tração, estes foram realizados em um equipamento modelo 4507 (Instron), com célula de carga de $250 \mathrm{kN}$ e velocidade de ensaio de 5 $\mathrm{mm} / \mathrm{min}$. As amostras também foram avaliadas por aquisição de imagens e medição da massa (balança Kern

\footnotetext{
${ }^{3}$ Motivo pelo qual estas varáveis são chamadas de "PARÂMETROS AUXILIARES" na Tabela 2, isto é, são parâmetros de importância, que ao contrário de outros de grande relevância para o processo que foram mantidos fixos, foram pontualmente configurados para garantir os estudos sobre os ângulos de varredura.
} 
als, máx 250g e 0,1 mg de resolução).

As análises mecânicas com PLA e PETG foram realizadas também para estudar as propriedades dos materiais (tensão máxima, deformação, módulo de elasticidade e coeficiente de Poisson) sem a influência das características construtivas do processo de Impressão 3D, citadas anteriormente. Para tal foram moídos os filamentos poliméricos (peletizados) e injetados corpos de prova (Figura 5), com as mesmas geometrias dos impressos, em uma máquina ARBURG 370E 600 (EUROMAP 170), com temperaturas de injeção de $215^{\circ} \mathrm{C}$ e $235^{\circ} \mathrm{C}$, respectivamente para o PLA e o PETG. Diferentemente das temperaturas de processamento, que foram configuradas iguais às utilizadas na Impressão 3D para cada um dos polímeros, os demais parâmetros e condições de injeção foram mantidos iguais para ambos os materiais: tempo e temperatura de secagem dos pellets $\left(24 \mathrm{~h}\right.$ a $\left.50^{\circ} \mathrm{C}\right)$, diâmetro da rosca da injetora $(30 \mathrm{~mm})$, vazão de injeção $\left(20 \mathrm{~cm}^{3}\right)$, tempo de recalque $(9$ s), tempo de resfriamento (55 s), pressão de injeção (1200 bar), volume de descompressão $\left(5 \mathrm{~cm}^{3}\right)$, força de fechamento $(450 \mathrm{kN})$, e temperatura do molde $\left(30^{\circ} \mathrm{C}\right)$.

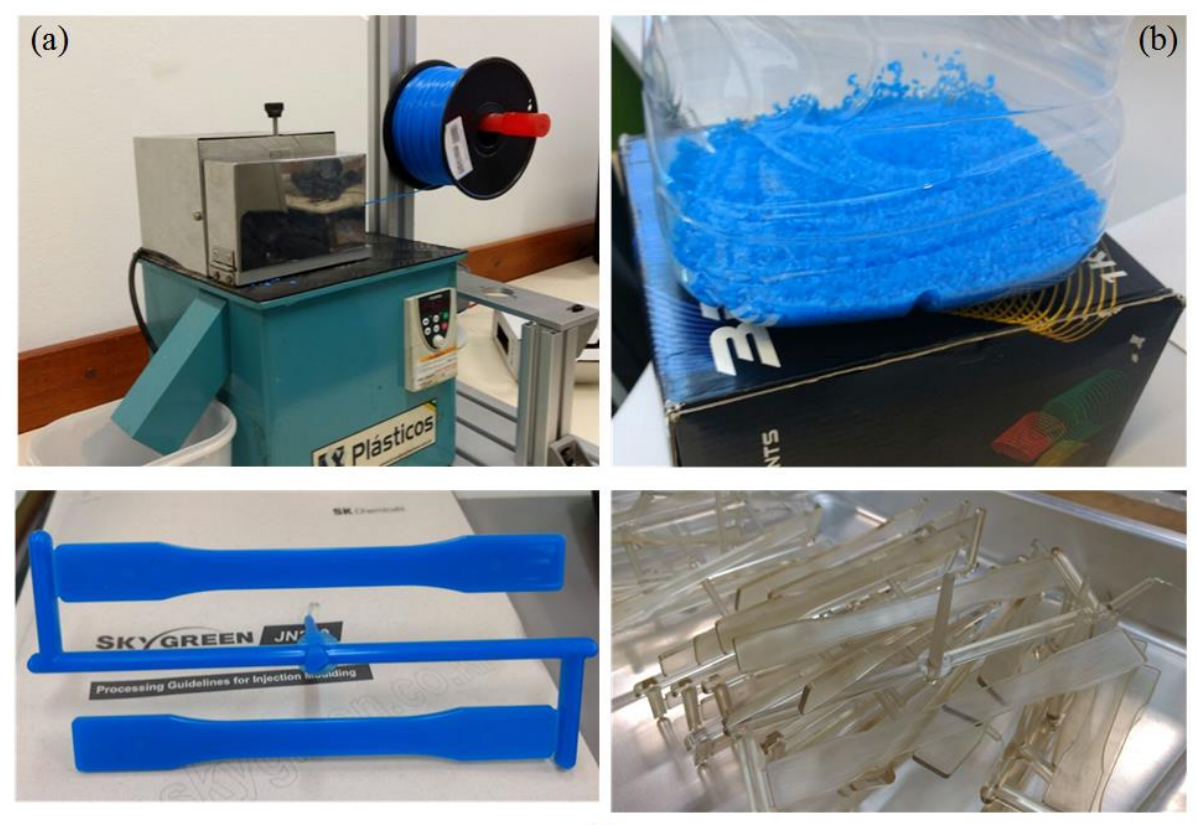

(c)

Figura 5: Processo de moagem (a), filamentos moídos (b) e (c) peças injetadas em PLA azul e PETG.

Os ensaios de tração dos componentes injetados, em um total de cinco por cada material, foram feitos em um equipamento modelo $250 \mathrm{kN}$ (MTS), com célula de carga de $10 \mathrm{kN}$ e velocidade de ensaio de 5 $\mathrm{mm} / \mathrm{min}$. Para a medição do coeficiente de Poisson foram testadas mais três amostras de PLA e PETG, cujas deformações longitudinais e transversais foram adquiridas por análise de correlação de imagem (equipamento com resolução das câmeras: 4,5 megapixels). E assim como nas amostras impressas, também foi medida a massa dos corpos de prova, utilizando a balança já citada acima.

\section{RESULTADOS E DISCUSSÕES}

\subsection{Grupo 1: análises térmicas e químicas}

Inicialmente são apresentados os resultados da análise de TGA realizada nos filamentos de PLA e PETG (Figura 6). Com base nas curvas obtidas, as quais relacionam a variação do percentual de massa em função da temperatura, foram observadas as temperaturas de decomposição dos materiais. Pode-se observar que ambos os polímeros apresentam dois estágios de perda de massa, sendo o primeiro mais pronunciado. 

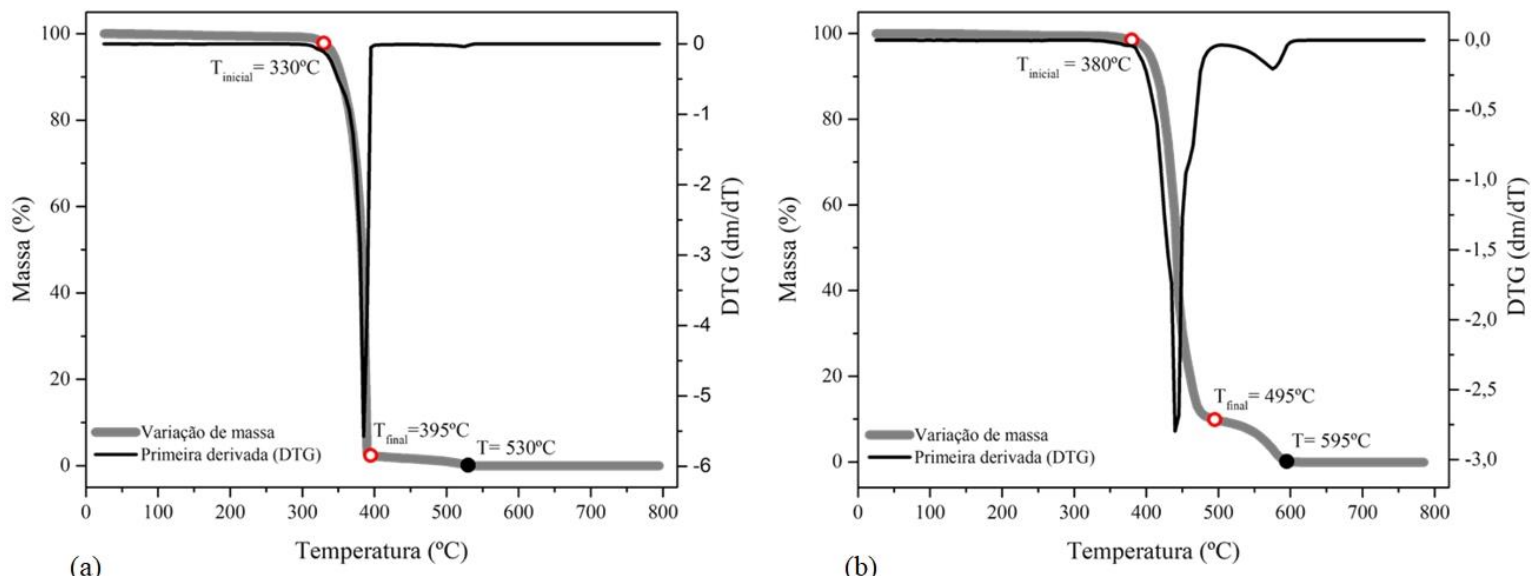

Figura 6: Resultados da análise de TGA com os filamentos de PLA (a) e PETG (b).

O principal estágio de decomposição térmica do PLA avaliado neste estudo inicia-se a uma temperatura $\left(T_{\text {inicial }}\right)$ de aproximadamente $330^{\circ} \mathrm{C}$ e finaliza $\left(T_{\text {final }}\right)$ em $395^{\circ} \mathrm{C}$, com uma variação da quantidade inicial de material de $98 \%$. Um segundo estágio de degradação ocorre entre $395^{\circ} \mathrm{C}$ e $530^{\circ} \mathrm{C}$, com uma perda de massa de $2 \%$, sendo verificada a degradação total do material após esta última temperatura. No caso do PETG, a degradação principal inicia-se em $380^{\circ} \mathrm{C}$, isto é, $50^{\circ} \mathrm{C}$ a mais do que o PLA. O final deste estágio de decomposição do PETG ocorre em $495^{\circ} \mathrm{C}, 100^{\circ} \mathrm{C}$ acima do PLA, com variação de $90 \%$ da massa inserida no ensaio. O segundo pico observado para o material, com uma variação de massa de $10 \%$, transcorreu no intervalo entre $495^{\circ} \mathrm{C}$ e $595^{\circ} \mathrm{C}$. Para temperaturas superiores a $595^{\circ} \mathrm{C}$ identifica-se a decomposição total do polímero, uma vez que a massa residual é zero.

Comparando os resultados obtidos com estudos da literatura, não limitados à impressão 3D, constatou-se que para o PLA a temperatura inicial de decomposição $\left(T_{\text {inicial }}=330^{\circ} \mathrm{C}\right)$ ficou próxima aos valores encontrados por SHIH e HUANG [53] e CARRASCO et al. [54], respectivamente, $342,2^{\circ} \mathrm{C}$ e $337,5^{\circ} \mathrm{C}$. No estudo de CARRASCO et al. [54], estes identificaram uma redução de $95 \%$ da massa inicial de PLA em $377^{\circ} \mathrm{C}$, resultados similares aos reportados neste trabalho.

Assim como para o PLA, no PETG também foram utilizados valores de referência para confrontar com os resultados encontrados. CHEN et al. [55] avaliaram pela técnica de TGA a temperatura de decomposição do PETG com diferentes composições químicas e obtiveram valores de temperatura inicial de degradação entre $(401,2 \text { e } 405,7)^{\circ} \mathrm{C}$, intervalo este que se aproxima ao valor observado no presente estudo. Ainda para efeitos de comparação, PASZKIEWICZ et al. [56] avaliaram a degradação térmica do PETG em duas condições de atmosfera no ensaio de TGA, inerte e oxidante (ar sintético), e verificaram que as temperaturas para uma perda de $90 \%$ da massa inicial foram, respectivamente, $602,9^{\circ} \mathrm{C}$ e $519,8^{\circ} \mathrm{C}$. Neste estudo, para o mesmo valor de redução de massa e utilizando-se ar sintético, a temperatura final de degradação já mencionada foi de $495^{\circ} \mathrm{C}$, indicando que essa atmosfera acelera o processo de decomposição térmica do PETG. Por fim, o segundo estágio de degradação do PETG, mais acentuado que o do PLA, também foi observado de forma semelhante no estudo de PASZKIEWICZ et al. [56]. Este efeito pode estar relacionado a um elemento da composição química do material que necessita de maior energia térmica para decompor totalmente a amostra inicial de filamento ou a resíduos da degradação

Seguindo a apresentação dos resultados das análises térmicas, na Figura 7 (a) e (b) são representados os termogramas de DSC obtidos para o PLA e o PETG em diferentes condições, isto é, filamentar (inicial), impressa e injetada. Os resultados da análise são sumarizados também na Tabela 3. Ao começar a interpretação dos dados, a partir das informações obtidas com os materiais na sua forma inicial, foi possível identificar o PLA como um polímero semicristalino e o PETG como amorfo. As temperaturas de transição vítrea $\left(T_{g}\right)$, fusão $\left(T_{m}\right)$, e cristalização $\left(T_{c}\right)$ do filamento de PLA foram, respectivamente, $61,9^{\circ} \mathrm{C}, 170,0{ }^{\circ} \mathrm{C}$, e $101,2^{\circ} \mathrm{C}$. Relativamente aos valores de $T_{g}$ e $T_{m}$ encontrados, estes são próximos aos relatados por SANTANA et al. [34] $-T_{g}$ de aproximadamente $65^{\circ} \mathrm{C}$ para filamentos de PLA pigmentados e $62^{\circ} \mathrm{C}$ para um filamento dito "natural"; e $T_{m}$ entre $(174$ e 175$){ }^{\circ} \mathrm{C}$ para os coloridos e $158^{\circ} \mathrm{C}$ para o "natural" — e SONG et al. [36] - $\mathrm{T}_{\mathrm{g}}$ igual a $61^{\circ} \mathrm{C}$ e $\mathrm{T}_{\mathrm{m}}$ a $168^{\circ} \mathrm{C}$ - os quais também caracterizaram o material no contexto da Impressão 3D. Em comparação ao PLA, o filamento de PETG avaliado dispõe de uma maior temperatura de transição vítrea, cerca de $14,3^{\circ} \mathrm{C}$ superior $\left(76,2^{\circ} \mathrm{C}\right)$. Este valor é equiparável aos resultados obtidos no experimento de LAM 
et al. [29] $\left(T_{g}=77^{\circ} \mathrm{C}\right)$, apesar de este não ser um estudo da área da Manufatura Aditiva.

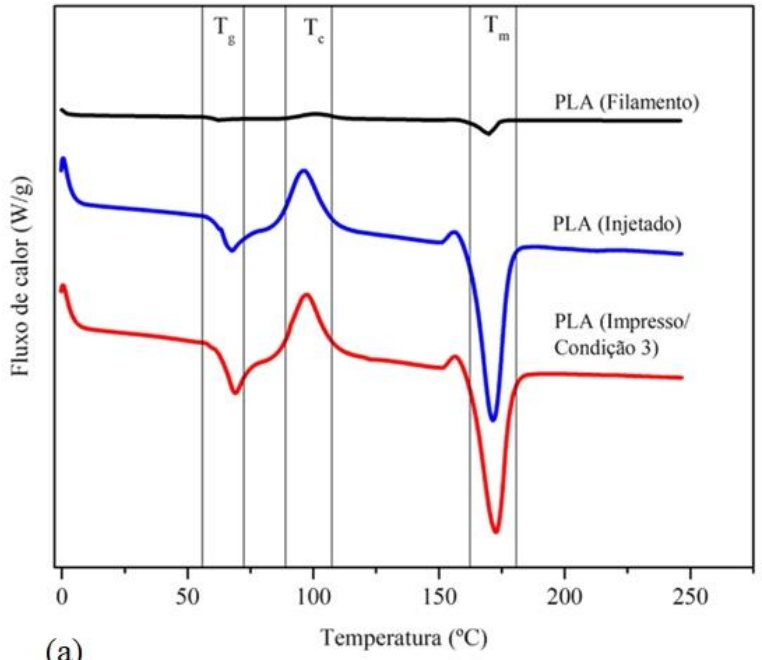

(a)

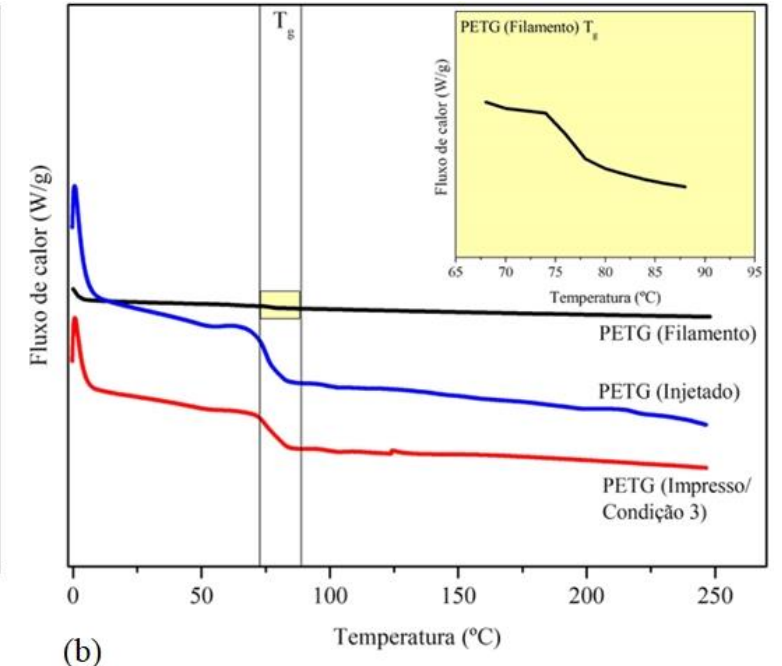

(b)

Figura 7: Curvas da análise de DSC, PLA (a) e PETG (b).

Tabela 3: Resultados da análise de DSC com o PLA e o PETG em diferentes estados.

\begin{tabular}{l|l|l|l|l|l}
\hline \multirow{2}{*}{ MATERIAL/ESTADO } & \multicolumn{5}{|c}{ RESULDADOS DA ANÁLISE DE DSC } \\
\cline { 2 - 6 } & $\boldsymbol{T}_{\boldsymbol{g}}\left({ }^{\circ} \boldsymbol{C}\right)$ & $\boldsymbol{T}_{\boldsymbol{m}}\left(^{\circ} \boldsymbol{C}\right)$ & $\boldsymbol{T}_{\boldsymbol{c}}\left({ }^{\circ} \boldsymbol{C}\right)$ & $\Delta \mathbf{H}_{\mathrm{f}}(\mathbf{J} / \mathbf{g})$ & $\boldsymbol{X}_{\boldsymbol{c}}(\%)$ \\
\hline PLA/Filamento & 61,9 & 170,0 & 101,2 & 34,9 & 37,5 \\
\hline PLA/Injetado & 64,3 & 171,4 & 96,3 & 40,0 & 43,0 \\
\hline PLA/Impresso & 66,9 & 172,6 & 97,4 & 38,9 & 41,8 \\
\hline PETG/Filamento & 76,2 & - & - & - & - \\
\hline PETG/Injetado & 75,3 & - & - & - & - \\
\hline PETG/Impresso & 75,0 & - & - & - & - \\
\hline
\end{tabular}

O comportamento térmico do PLA após o processamento pelas técnicas de Impressão 3D e moldagem por injeção foi alterado no sentindo de aumento das temperaturas de transição vítrea e de fusão, e redução da temperatura de cristalização em relação ao estado inicial. A diferença entre a $T_{g}$ do filamento e da amostra obtida da peça injetada foi de aproximadamente $+2,4^{\circ} \mathrm{C}(\approx+4 \%)$. Já na comparação com a porção oriunda do componente impresso a variação foi maior, aproximadamente $+5^{\circ} \mathrm{C}(\approx+8 \%)$. No caso da fusão as diferenças foram menores, cerca de $+1,4^{\circ} \mathrm{C}(\approx+0,8 \%)$ para a injetada, e $+2,6^{\circ} \mathrm{C}(\approx+1,5 \%)$ para a impressa. A redução da temperatura de cristalização do PLA injetado e impresso, em relação ao filamento, foi próxima a $4,9^{\circ} \mathrm{C}(\approx-5 \%)$ e $-3,8^{\circ} \mathrm{C}(\approx-4 \%)$, respectivamente. Entre si, o elemento impresso apresentou resultados ligeiramente maiores do que o injetado: $+2,6^{\circ} \mathrm{C}(\approx+4 \%),+1,2^{\circ} \mathrm{C}(\approx+0,7 \%) \mathrm{e}+1,1^{\circ} \mathrm{C}(\approx+1 \%)$, nesta ordem para $T_{g}, T_{m}$ e $T_{c}$. Ainda sobre a análise de DSC com o PLA, a partir da equação 1 foi possível calcular o grau de cristalinidade $\left(X_{c}\right)$ (Tabela 3 ) do polímero de modo a avaliar a influência das tecnologias de fabricação às quais o material foi submetido (isto é, no primeiro ciclo de aquecimento no ensaio).

De acordo com os resultados, constatou-se que o grau de cristalinidade do PLA aumentou, em relação a sua condição inicial, devido à ação dos processos de manufatura utilizados neste estudo. Do valor calculado para o polímero enquanto filamento $(37,5 \%)$, para o material após à impressão e a injeção, verificou-se um aumento na cristalinidade de aproximadamente $+4,3 \%$ e $+5,5 \%$, para cada tecnologia respectivamente. Esse resultado pode ser atribuído à maior organização molecular decorrentes dos processos de manufatura (injeção e Impressão 3D). Segundo SONG et al. [36], uma justificativa para o baixo grau de cristalinidade dos filamentos (condição inicial do material para o processo de Impressão 3D) se deve ao resfriamento rápido durante a fabricação deste produto, não permitindo assim um arrefecimento lento que colabore para o processo de cristalização. Entretanto, os efeitos introduzidos pelas variáveis da moldagem por injeção e da Impressão 3D (considerando a Condição 3, da qual se avaliou a cristalinidade), na comparação entre si, não foram muito 
significativos para as alterações no grau de cristalinidade do PLA, uma vez que se observa uma diferença mínima de aproximadamente $1,2 \%$.

Diferentemente do PLA, o PETG mostrou-se um material mais estável, isto é, menos suscetível a mudanças nas características térmicas em função da influência dos processos de fabricação ao qual foi submetido. A variação na temperatura de transição vítrea, no sentido de redução, foi de apenas $-0,9^{\circ} \mathrm{C}(\approx-1,2 \%)$ da $\mathrm{T}_{\mathrm{g}}$ do filamento para a da amostra da peça injetada, e de $-1,2^{\circ} \mathrm{C}(\approx-1,6 \%)$ para o fragmento do modelo impresso.

Na Figura 8 (a) e (b) são apresentadas as curvas da análise de FTIR, assim como feito para o DSC, dos polímeros nas diferentes condições analisadas (filamento, impressa e injetada). Para complementar a apresentação dos resultados, na Tabela 4 são disponibilizados os principais picos, números de ondas, identificados no ensaio de espectroscopia e representados nas regiões delimitadas pelos retângulos (1 a 5) da Figura 8 (a) e (b).

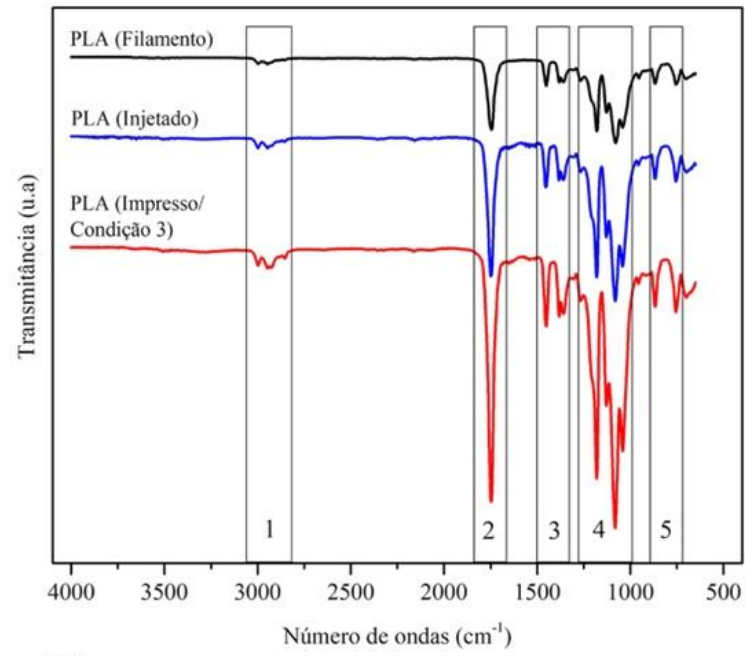

(a)

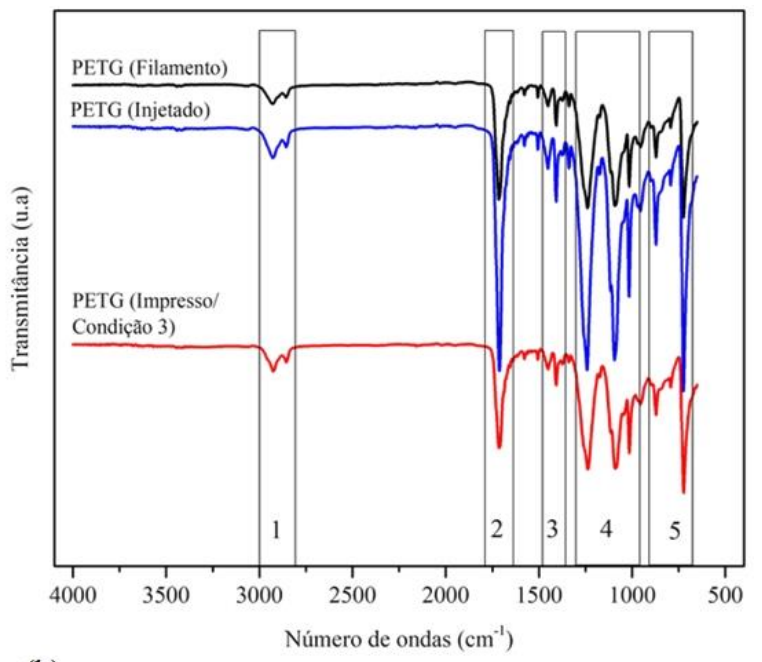

(b)

Figura 8: Curvas da análise de FTIR, PLA (a) e PETG (b).

Tabela 4: Resultados da análise de FTIR por regiões delimitadas nas curvas.

\begin{tabular}{l|l|l|l|l|l}
\hline \multirow{2}{*}{ MATERIAL/ESTADO } & \multicolumn{5}{|c}{ NÚMERO DE ONDAS (cm $\left.{ }^{-1}\right)$} \\
\cline { 2 - 6 } & REGIÃO 1 & REGIÃO 2 & REGIÃO 3 & REGIÃO 4 & REGIÃO 5 \\
\hline PLA/Filamento & $2996 ; 2945$ & 1745 & $1451 ; 1381 ; 1357$ & $1180 ; 1128 ; 1079 ; 1041$ & $867 ; 755$ \\
\hline PLA/Injetado & $2997 ; 2947 ; 2856$ & 1748 & $1453 ; 1383 ; 1359$ & $1181 ; 1128 ; 1081 ; 1041$ & $868 ; 755$ \\
\hline PLA/Impresso & $2997 ; 2944 ; 2855$ & 1747 & $1451 ; 1382 ; 1358$ & $1181 ; 1128 ; 1081 ; 1042$ & $867 ; 755$ \\
\hline PETG/Filamento & $2927 ; 2856$ & 1715 & $1451 ; 1408$ & $1239 ; 1092 ; 1016$ & $873 ; 725$ \\
\hline PETG/Injetado & $2926 ; 2856$ & 1712 & $1451 ; 1408$ & $1242 ; 1094 ; 1017$ & $873 ; 724$ \\
\hline PETG/Impresso & $2925 ; 2855$ & 1713 & $1451 ; 1408$ & $1237 ; 1090 ; 1016$ & $872 ; 724$ \\
\hline
\end{tabular}

Em uma análise geral dos espectros observados para o PLA, verificou-se que os valores se encontram próximos aos resultados obtidos nos estudos de SANTANA et al. [34] e CUIFFO et al. [35], os quais também avaliaram o material no contexto da Impressão 3D. Para auxiliar na interpretação dos números de ondas, tal como nas análises térmicas, outras referências sobre o PLA, e que não se limitam ao cenário da Manufatura Aditiva, foram utilizadas. Os picos contidos na faixa de valores da Região 1 correspondem ao estiramento - $\mathrm{CH}$ (grupo $\mathrm{CH}_{3}$ ) [34,35] [57-59]. As bandas da Região 2 foram associadas ao estiramento carbonilo $\mathrm{C}=\mathrm{O}$ do grupo -CO-O- do PLA [34,57] [60-63]. O intervalo observado na Região 3 está relacionado, de acordo com o padrão apresentado por CHOKSI e DESAI [59] $\left(1375 \mathrm{~cm}^{-1}\right.$ a $\left.1475 \mathrm{~cm}^{-1}\right)$, às vibrações de flexão $\mathrm{CH}_{3}$. $\mathrm{Na}$ Região 4 são encontrados espectros classificados como o estiramento C-O-C [64-68]. A Região 5, por fim, apresenta uma banda em $867 \mathrm{~cm}^{-1}$, que segundo CUIFFO et al. [35] e KISTER et al. [69] equivale à vibração C-COO, e outra em $775 \mathrm{~cm}^{-1}$, contida no intervalo entre $\left(733\right.$ e 756) $\mathrm{cm}^{-1}$ descrito por XU et al. [70] como vibrações esqueléticas dos grupos metileno. 
Diferentemente do PLA, em que foram encontrados artigos no âmbito da Impressão 3D, no caso do PETG a maior parte dos estudos envolvendo a análise de FTIR foram para o material em aplicações gerais. Com base na literatura os espectros do material, para cada região, foram interpretados como: (i) as bandas da Região 1, (2925 a 2927) $\mathrm{cm}^{-1}$ e (2855 a 2856) $\mathrm{cm}^{-1}$, dizem respeito ao estiramento C-H, simétrico e assimétrico, devido à presença de metileno no copolímero PETG [55,71]; (ii) o pico identificado na Região 2, para o material nas diferentes condições, equivale ao estiramento $\mathrm{C}=\mathrm{O}$ do grupo éster [55, 56] [72-74]; (iii) a Região 3 apresenta espectros em $1451 \mathrm{~cm}^{-1}$ e $1408 \mathrm{~cm}^{-1}$, que correspondem, respectivamente, a um pico de flexão $\mathrm{CH}_{2}$ e a um pico C-H [55, 73] [75,76]; (iv) para a Região 4 os números de onda de $1237 \mathrm{~cm}^{-1}$ a $1242 \mathrm{~cm}^{-1}$ são classificados como um estiramento C(O)-O [56,77], os valores em (1090 a 1094) $\mathrm{cm}^{-1}$ são atribuídos ao estiramento simétrico C-O (glicol) [78] [73,79], e as bandas em $1016 \mathrm{~cm}^{-1}$ e $1017 \mathrm{~cm}^{-1}$ representam a flexão CH no plano do anel aromático [73] [80,81]; (v) já os espectros em (872 a 873) $\mathrm{cm}^{-1}$ e $\left(724\right.$ a 725) $\mathrm{cm}^{-1}$, Região 5, se referem, nesta ordem, à flexão C-H fora do plano do anel benzeno, e à flexão C-H fora do plano do anel mais a flexão $\mathrm{C}=\mathrm{O}[73,74]$ [80]. Para ambos os materiais, os espectros obtidos para as amostras impressas e injetadas são similares aos do filamento, não sendo observadas variações significativas após o processamento. $\mathrm{O}$ fato sugere que as condições de fabricação (equipamentos, parâmetros, ambiente, etc.) utilizadas neste estudo não alteraram os grupos funcionais presentes e não promoveram deslocamentos que possibilitem avaliar modificações químicas e a presença de agentes contaminantes nos polímeros.

\subsection{Grupo 2: análises mecânicas}

Os resultados obtidos nos ensaios de tração das amostras de PLA e PETG injetadas são representados graficamente nas Figuras 9 e 10, (a) e (b), respetivamente para tensão máxima $\left(\sigma_{\text {máx }}\right)$ e deformação na tensão máxima $\left(\varepsilon_{\sigma \text { máx }}\right)$, e módulo de Young $(E)$ e coeficiente de Poisson $(v)$. Além de uma síntese das propriedades mecânicas avaliadas, na Tabela 5 são apresentados também os valores médios de massa das amostras.

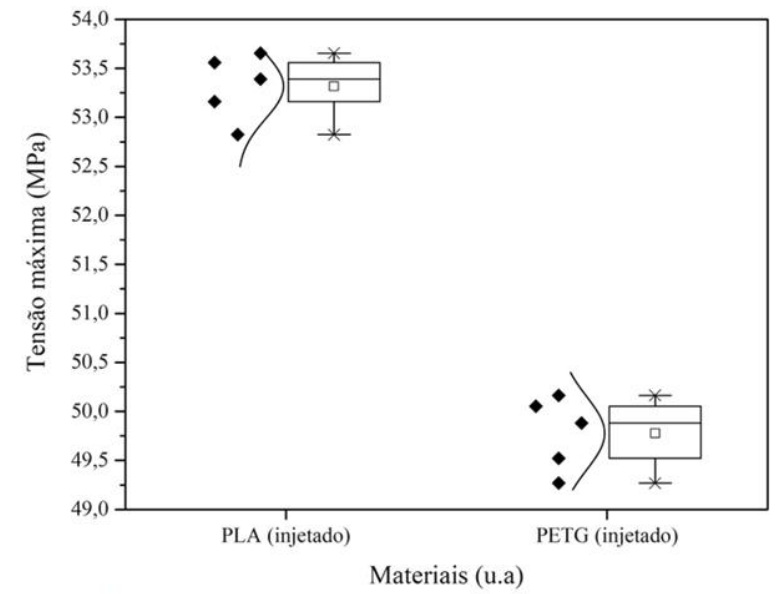

(a)

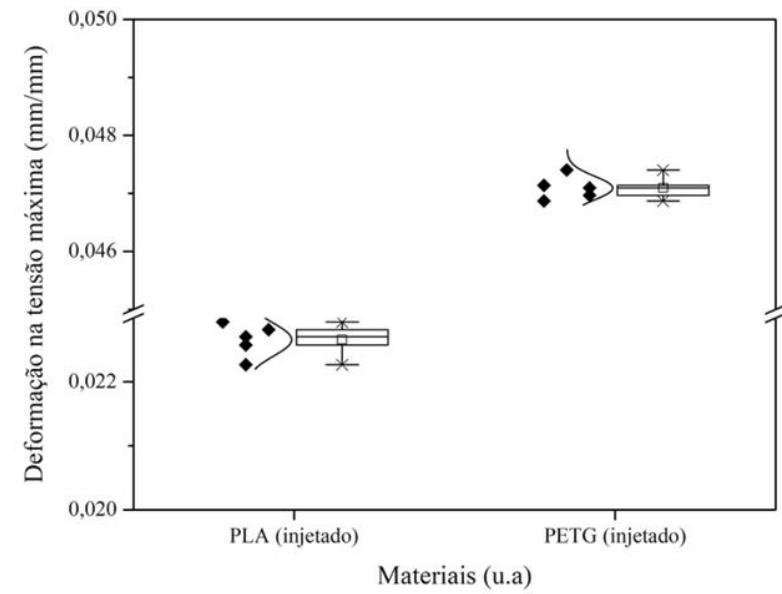

(b)

Figura 9: Médias da tensão máxima (a) e da deformação na tensão máxima (b). 


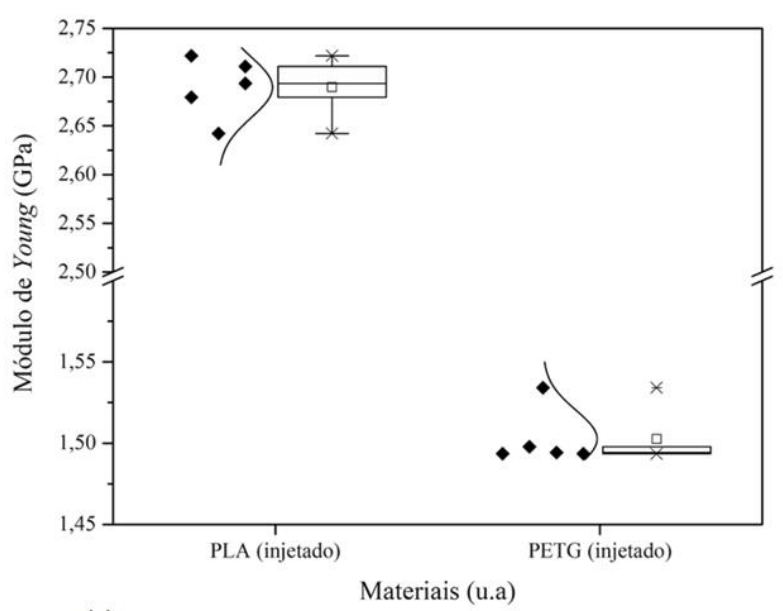

(a)

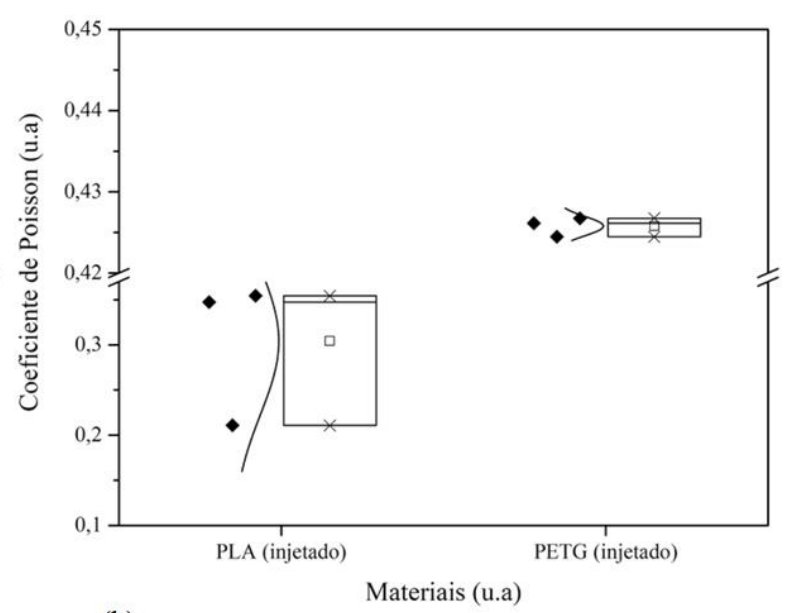

(b)

Figura 10: Média do módulo de Young (a) e do coeficiente de Poisson (b).

Tabela 5: Resultados obtidos nos ensaios de tração e medição da massa das amostras injetadas.

\begin{tabular}{l|l|l}
\hline PROPRIEDADES & PLA & PETG \\
\hline$\sigma_{\text {máx }}(\mathrm{MPa})$ & $53,32 \pm 0,33$ & $49,78 \pm 0,37$ \\
\hline$\varepsilon_{\sigma \text { máx }}(\mathrm{mm} / \mathrm{mm})$ & $0,02 \pm 2,6 \mathrm{E}-4$ & $0,05 \pm 2,0 \mathrm{E}-4$ \\
\hline$E(\mathrm{GPa})$ & $2,69 \pm 0,03$ & $1,50 \pm 0,02$ \\
\hline$v$ (u.a) & $0,30 \pm 0,08$ & $0,43 \pm 0,001$ \\
\hline Massa $(g)$ & $10,40 \pm 0,03$ & $10,78 \pm 0,02$ \\
\hline
\end{tabular}

Em uma análise geral das informações encontradas com os ensaios de tração das amostras injetadas (Tabela 5), constatou-se que o PLA apresenta, na maior parte dos casos, propriedades mecânicas superiores ao PETG. A tensão máxima, por exemplo, é aproximadamente 7\% maior que a do PETG, entretanto, este último dispõe de uma maior capacidade de deformação até atingir o ponto máximo, praticamente o dobro, quando comparado ao PLA.

Uma das maiores diferenças identificadas na comparação entre os dois materiais foi em relação à rigidez dos polímeros. Considerando os valores do módulo de Young (elasticidade), o PLA apresentou-se como um material cerca de 1,8 vezes, ou 79\%, mais rígido que o PETG ${ }^{4}$. Além do módulo de elasticidade, o coeficiente de Poisson, dentro de determinados intervalos, também permite classificar os materiais quanto a sua rigidez ou flexibilidade. Informações da literatura descrevem: "o coeficiente de Poisson para a maioria dos polímeros frágeis é de aproximadamente 0,3 ; para polímeros flexíveis encontra-se em aproximadamente 0,45 [83]"; "Valores comuns para a faixa de materiais de borracha estão entre 0,49 e 0,4999; para plásticos entre 0,20 e 0,40 [84]"; "Polímeros flexíveis, polímeros rígidos, e cargas sólidas têm valores próximos a 0,4, 0,3 e 0,3 respectivamente [85]". Com base nos valores de referência, confirma-se através da análise do coeficiente de Poisson, a rigidez do PLA $(0,3)$ e a flexibilidade do PETG (0,43). A flexibilidade do PETG em comparação ao PLA, pode estar relacionada também ao fato daquele polímero apresentar uma estrutura do tipo amorfa, conforme conceitos descritos por BANIK [86].

Destaca-se ainda que ao se compararem as respostas aos ensaios de tração para o PLA e o PETG, todos os itens avaliados apresentam diferenças estatísticas entre si, considerando um confronto correspondente entre materiais (tensão máxima do PLA vs. tensão máxima do PETG; módulo de Young do PLA vs. módulo de Young do PETG, etc.). Tais diferenças são associadas as baixas dispersões dos valores em torno da média, o que faz com que os intervalos estatísticos não se interceptem em pontos comuns — Figuras 9 e 10, (a) e (b).

\footnotetext{
${ }^{4}$ De acordo com CANEVAROLO [82] o módulo de Young está diretamente relacionado com a rigidez do polímero, isto é, quanto maior for o valor do módulo maior será a rigidez do polímero.
} 
Relativamente à massa das amostras, para um mesmo volume das peças injetadas $\left(8,4 \mathrm{~cm}^{3}\right)$, observa-se uma pequena diferença na qual o PETG apresenta cerca de $0,38 \mathrm{~g}(\approx+4 \%)$ a mais que o PLA, variação esta que pode estar relacionada ao fato de que o PETG é mais denso que o PLA. A partir da relação entre a massa e o volume das amostras foi possível determinar a densidade aparente dos materiais: aproximadamente 1,24 $\mathrm{g} / \mathrm{cm}^{3}$ para o PLA e $1,28 \mathrm{~g} / \mathrm{cm}^{3}$ para o PETG. Os valores são muitos semelhantes aos disponíveis na literatura para o PLA $\left(1,25 \mathrm{~g} / \mathrm{cm}^{3}\right)[34,87]$ e o PETG $\left(1,27 \mathrm{~g} / \mathrm{cm}^{3}\right)$ [74].

Apresentadas as propriedades mecânicas dos materiais, oriundas de amostras totalmente sólidas (injetadas), a seguir (Tabela 6) são mostrados os resultados encontrados nos testes a tração e na medição da massa das peças em PLA e PETG, influenciados pelas características do processo de Impressão 3D por extrusão.

Tabela 6: Resultados obtidos nos ensaios de tração e medição da massa das amostras impressas.

\begin{tabular}{l|l|l|l|l|l|l}
\hline PROPRIEDADES & PLA (C1) & PLA (C2) & PLA (C3) & PETG (C1) & PETG (C2) & PETG (C3) \\
\hline$\sigma_{\text {máx }}(\mathrm{MPa})$ & $43,50 \pm 0,72$ & $36,61 \pm 0,80$ & $49,34 \pm 1,12$ & $32,15 \pm 0,67$ & $28,21 \pm 1,70$ & $41,10 \pm 0,14$ \\
\hline$\varepsilon_{\sigma \text { máx }}(\mathrm{mm} / \mathrm{mm})$ & $0,02 \pm 2,8 \mathrm{E}-4$ & $0,01 \pm 4,2 \mathrm{E}-4$ & $0,01 \pm 4,1 \mathrm{E}-4$ & $0,03 \pm 1,1 \mathrm{E}-3$ & $0,02 \pm 1,4 \mathrm{E}-3$ & $0,03 \pm 3,0 \mathrm{E}-4$ \\
\hline$E(\mathrm{GPa})$ & $3,30 \pm 0,12$ & $3,17 \pm 0,06$ & $3,59 \pm 0,03$ & $1,55 \pm 0,05$ & $1,63 \pm 0,02$ & $1,92 \pm 0,01$ \\
\hline Massa $(\mathrm{g})$ & $10,18 \pm 0,03$ & $9,82 \pm 0,05$ & $9,90 \pm 0,07$ & $9,96 \pm 0,08$ & $9,81 \pm 0,04$ & $9,79 \pm 0,02$ \\
\hline
\end{tabular}

Como as amostras de ambos os materiais foram construídas com variações paramétricas, as respostas apresentadas na Tabela 6 foram avaliadas estatisticamente pelo método da análise de variância (ANOVA), com o objetivo de identificar se os diferentes ângulos de varreduras utilizados foram significativos para as alterações no comportamento mecânico e na massa das peças (Tabela 7). As médias de cada resposta, para os diferentes ÂV utilizados (nomeados por C1, C2 e C3), são apresentadas nas Figuras 11 e 12.

Tabela 7: Resumo da análise de variância (ANOVA) $(\alpha=95 \%)^{5}$.

\begin{tabular}{|c|c|c|c|c|c|c|c|c|c|c|c|c|}
\hline \multirow[t]{2}{*}{ FONTE DE VARIAÇÃO } & \multicolumn{6}{|c|}{ ANOVA - TENSÃO MÁXIMA (MPa) PLA } & \multicolumn{6}{|c|}{ ANOVA - TENSÃO MÁXIMA (MPa) PETG } \\
\hline & GL & SQ & v & $\mathbf{F}$ & $\mathbf{P}$ & $\mathrm{PC}(\%)$ & GL & SQ & $\mathbf{v}$ & $\mathbf{F}$ & $\mathbf{P}$ & $\mathrm{PC}(\%)$ \\
\hline Entre grupos & 2 & 406,16 & 203,08 & 251,62 & 0,00 & 97,28 & 2 & 436,49 & 218,24 & 194,40 & 0,00 & 96,51 \\
\hline Dentro dos grupos & 12 & 9,69 & 0,81 & 1 & & 2,72 & 12 & 13,47 & 1,12 & 1 & & 3,49 \\
\hline Total & 14 & 415,85 & & & & 100 & 14 & 449,96 & & & & 100 \\
\hline FONTE DE VARIAÇÃO & \multicolumn{6}{|c|}{ ANOVA - DEF. T. MÁX $(\mathrm{mm} / \mathrm{mm})$ PLA } & \multicolumn{6}{|c|}{ ANOVA - DEF. T. MÁX (mm/mm) PETG } \\
\hline Entre grupos & 2 & $9,3 \mathrm{E}-6$ & $4,7 \mathrm{E}-6$ & 33,04 & 0,00 & 82,07 & 2 & 0,001 & $3,0 \mathrm{E}-4$ & 271,14 & 0,00 & 97,47 \\
\hline Dentro dos grupos & 12 & $1,7 \mathrm{E}-6$ & $1,4 \mathrm{E}-7$ & 1 & & 17,93 & 12 & $1,3 \mathrm{E}-5$ & $1,1 \mathrm{E}-6$ & 1 & & 2,53 \\
\hline Total & 14 & & & & & 100 & 14 & & & & & 100 \\
\hline FONTE DE VARIAÇÃO & \multicolumn{6}{|c|}{ ANOVA - MÓDULO DE YOUNG (GPa) PLA } & \multicolumn{6}{|c|}{ ANOVA - MÓDULO DE YOUNG (GPa) PETG } \\
\hline Entre grupos & 2 & 0,47 & 0,23 & 36,50 & 0,00 & 83,53 & 2 & 0,37 & 0,19 & 200,70 & 0,00 & 96,61 \\
\hline Dentro dos grupos & 12 & 0,08 & 0,01 & 1 & & 16,47 & 12 & 0,01 & 0,001 & & & 3,39 \\
\hline Total & 14 & 0,55 & & & & 100 & 14 & & & & & 100 \\
\hline FONTE DE VARIAÇÃO & \multicolumn{6}{|c|}{ ANOVA - MASSA (g) PLA } & \multicolumn{6}{|c|}{ ANOVA - MASSA (g) PETG } \\
\hline Entre grupos & 2 & 0,36 & 0,18 & 68,00 & 0,00 & 90,54 & 2 & 0,08 & 0,04 & 15,18 & 0,00 & 66,95 \\
\hline Dentro dos grupos & 12 & 0,03 & 0,003 & & & 9,46 & 12 & 0,03 & 0,003 & & & 33,05 \\
\hline Total & 14 & & & & & 100 & 14 & & & & & \\
\hline
\end{tabular}

\footnotetext{
${ }^{5}$ Para complementar os resultados da análise de variância foram realizados testes de Tukey para a comparação entre as médias (post hoc) dos níveis associados ao fator ângulo de varredura. As condições que apresentaram alguma igualdade estatística são descritas na Tabela 8 , disponibilizada na seção 7.ANEXO.
} 


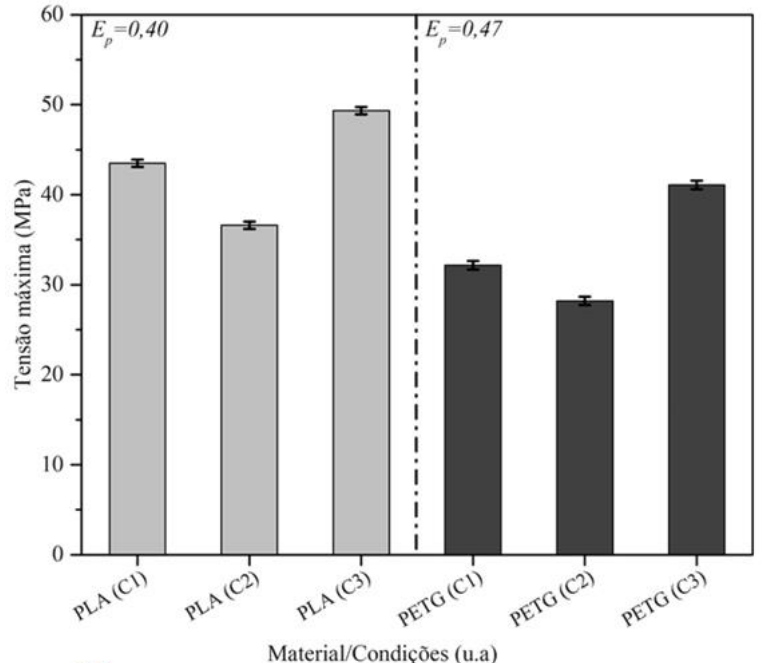

(a)

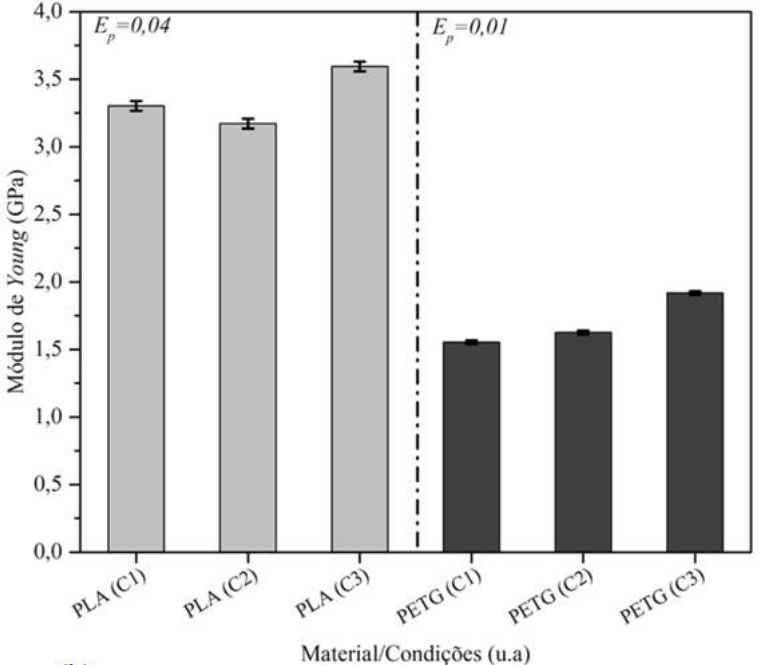

(b)

Figura 11: Média da tensão máxima (a) e do módulo de Young (b) em função dos níveis do ângulo de varredura ${ }^{6}$.

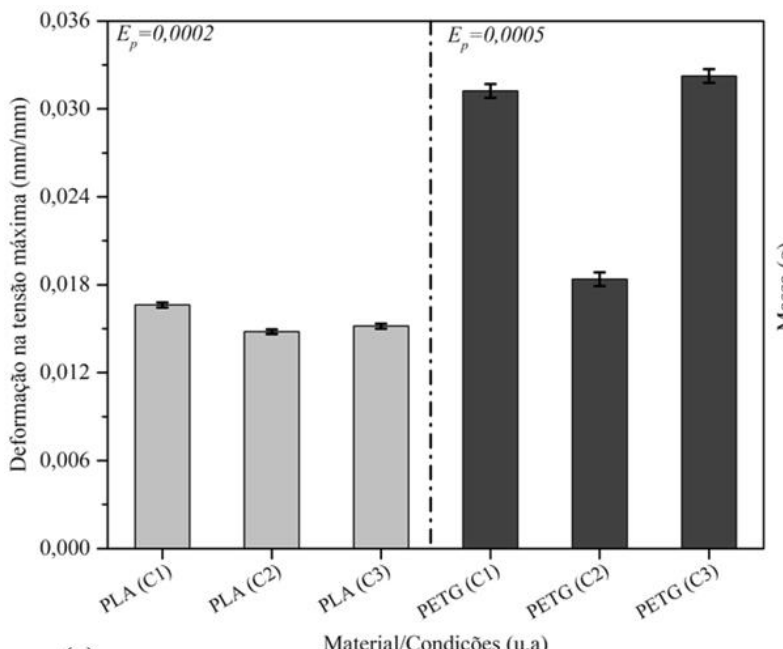

(a)

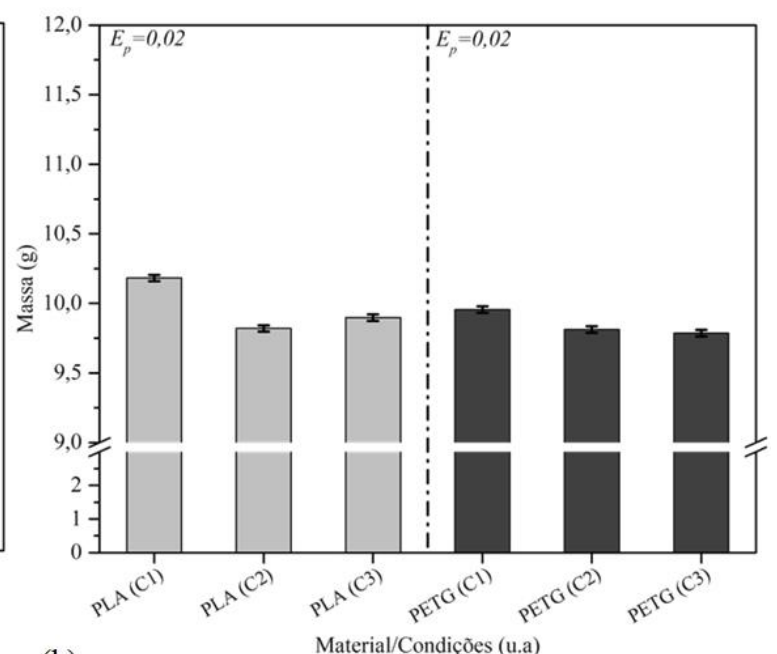

(b)

Figura 12: Média da deformação na tensão máxima (a) e da massa (b) em função dos níveis do ângulo de varredura.

As informações fornecidas pela ANOVA mostram que todas as respostas investigadas foram influenciadas pelo ângulo de varredura. Relativamente à tensão máxima, em ambos os materiais os melhores resultados foram associados à configuração unidirecional (C3) $\left(\hat{\mathrm{AV}}=0^{\circ}\right)$ — Figura 11 (a)—, comportamento este também observado em estudos clássicos da tecnologia de Impressão 3D por extrusão, como o de AHN et al. [88]. Tal efeito é relacionado ao fato de que todos os filamentos depositados, dentro e entre as camadas, encontravam-se na mesma direção e alinhados no sentido de aplicação da carga (axial) no ensaio de tração. Segundo BELLINI e GÜÇERI [89] a arquitetura interna de peças fabricadas por FDM são semelhantes a uma estrutura compósita de fibras reforçadas, na qual os filamentos individuais são mais resistentes na direção axial, como as fibras de um compósito; por outro lado, as peças apresentam um comportamento mais fraco na região de adesão entre filamento-filamento ou entre as camadas.

O conceito descrito pelos autores auxilia na compreensão dos efeitos observados neste trabalho. Como todos os filamentos da C3 estão dispostos, em conjunto, ao longo da direção axial, aumentou-se a capacidade de carga das peças impressas, além de distribuir a maior parte da força ao longo dos filamentos, e não diretamente na linha de união entre eles. O somatório desses efeitos faz com que a condição unidirecional ofereça maior resistência à tração aos componentes em PLA e PETG quando comparados às peças com os mesmos

\footnotetext{
6 “ $E_{p}$ " corresponde ao erro padrão, obtido na análise de variância.
} 
materiais fabricadas com as condições de fabricação $\mathrm{C} 1\left(45^{\circ} /-45^{\circ}\right)-\mathrm{C} 3$ aproximadamente $13 \%$ maior que $\mathrm{C} 1$ no PLA e cerca de $28 \%$ no PETG - e C2 $\left(0^{\circ} / 90^{\circ}\right)$ - C 3 aproximadamente $35 \%$ superior no PLA e aproximadamente $46 \%$ para o PETG. A relação entre o alinhamento dos filamentos e a direção de aplicação dos esforços de tração com os melhores valores de tensão máxima pode também ser utilizada para justificar os maiores valores da Condição 1 frente a Condição 2. Especificamente sobre $\mathrm{C} 2$, apesar de ter camadas nas quais os filamentos encontram-se totalmente alinhados com a carga de tração, estas alternam-se com camadas em que as estruturas são depositadas em posições que promovem a aplicação de forças durante o teste na linha de adesão entre filamentos vizinhos, isto é, a região mais fraca descrita por BELLINE e GÜÇERI [89]. Em outras palavras, as peças oriundas da Condição $2\left(\hat{\mathrm{A} V}=0^{\circ} / 90^{\circ}\right)$ dispõem de apenas $50 \%$ da sua estrutura com capacidade de suportar melhor cargas à tração (camadas em $0^{\circ}$ ).

Para ilustrar a situação descrita, na Figura 13 (a) e (b) são apresentadas duas imagens que representam respectivamente as secções transversais, após a fratura das amostras, de peças construídas com as condições C2 e C3 em PLA. Em ambas as imagens se verificou uma mudança na coloração inicial das peças, isto é, de azul, para branco, o que corresponde às regiões que foram mais estressadas durante o ensaio de tração. As amostras em PLA, por serem pigmentadas, foram selecionadas para a análise visual da região da fratura por evidenciar as alterações de cor nas zonas afetadas.

$\mathrm{Na}$ amostra fabricada com $\mathrm{C} 2$ este "esbranquiçamento" evidencia-se nos filamentos correspondentes às camadas em $0^{\circ}$, ou seja, alinhadas com a direção de tração. Já na fratura da amostra em $\mathrm{C} 3$, a mudança de coloração é mais branda, ou seja, não tão intensa como nos filamentos em $0^{\circ}$ de $\mathrm{C} 2$, e distribuída ao longo de toda a estrutura. Esta análise complementa visualmente as discussões anteriores baseadas nos conceitos da literatura, de forma a confirmar que em C2 uma parcela menor de filamentos (branco mais intenso) foi responsável por garantir resistência às peças, e em $\mathrm{C} 3$ ocorreu uma coletividade dos elementos estruturais para suportar os efeitos do teste (branco menos intenso). Em termos de comparação de tensão máxima, os resultados do PLA nas condições 1, 2, e 3 foram aproximadamente 35\%, 30\%, e 20\% maiores que os do PETG nas mesmas condições.

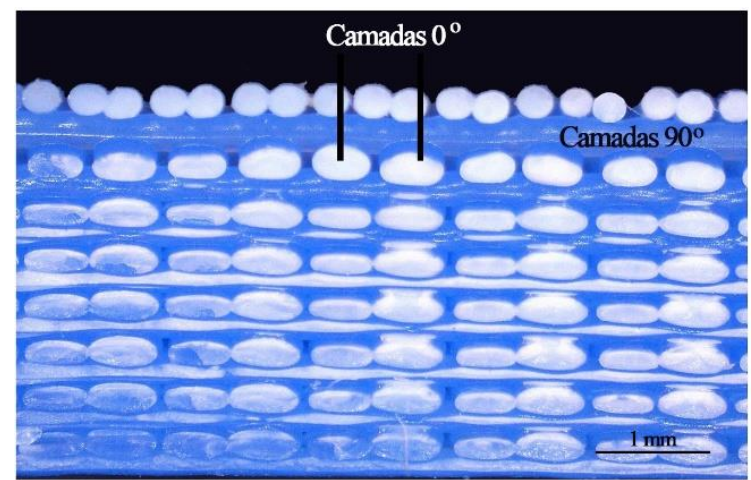

(a)

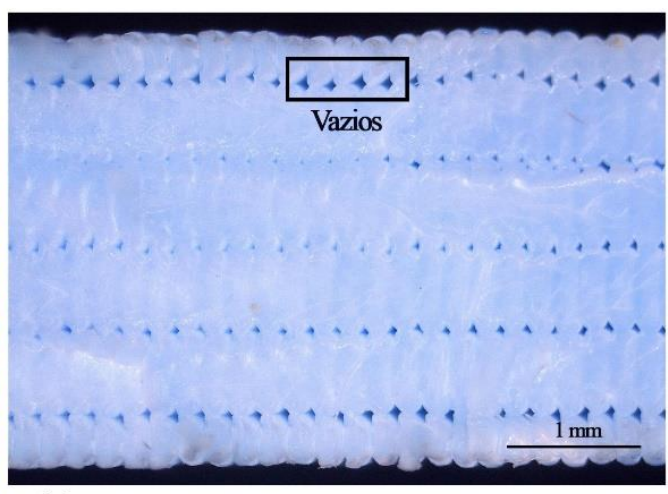

(b)

Figura 13: Secção transversal da região de fratura, (a) Condição 2 e (b) Condição 3.

Relativamente ao módulo de Young, o comportamento quanto aos maiores valores, tanto para o PLA como para o PETG, foi semelhante aos encontrados na tensão máxima, isto é, para a Condição 3 (unidirecional). No caso do PETG constata-se claramente um crescimento no módulo de elasticidade das peças construídas de C1 para C3 - Figura 11 (b). No PLA, por outro lado, verificou-se, pelo método de comparação de médias de Tukey, que a média do módulo — Figura 11 (b) — das amostras fabricadas em C1 eram estatisticamente iguais às confeccionadas em $\mathrm{C} 2$. O que se entende é que para este material, as peças construídas com ângulos de varredura em $45^{\circ} /-45^{\circ}(\mathrm{C} 1)$ e $0^{\circ} / 90^{\circ}(\mathrm{C} 2)$ apresentam um comportamento semelhante na zona elástica quanto ao critério de rigidez, diferenciando-se pelo limite de transição, ou neste caso a tensão máxima. Comparativamente, entre as mesmas condições de fabricação, o PLA apresentou-se como um material aproximadamente 2 vezes mais rígido que o PETG, razão próxima à observada nas amostras injetadas.

Para ambos os materiais, dois fatores comuns podem ser observados: (i) as peças com filamentos unidirecionais são mais rígidas — apresentaram maior módulo de elasticidade —, e (ii) as amostras produzidas em C2 - apesar de em alguns casos como no PETG disporem de maior rigidez — são mais frágeis. A fragi- 
lidade das peças - considerando neste momento os efeitos ocorridos na zona plástica - obtidas na Condição 2, assim como na tensão máxima, se deve à presença das zonas fracas e de baixa capacidade de deformação, isto é a linha de adesão das camadas com ângulos de $90^{\circ}$, e perpendiculares a aplicação da carga de tração. Uma análise visual do módulo de Young (inclinação das curvas), bem como do comportamento frágil das amostras em C2, pode ser observada nas curvas tensão-deformação das peças nas Figuras 14 e 15 , respectivamente para o PLA e o PETG.
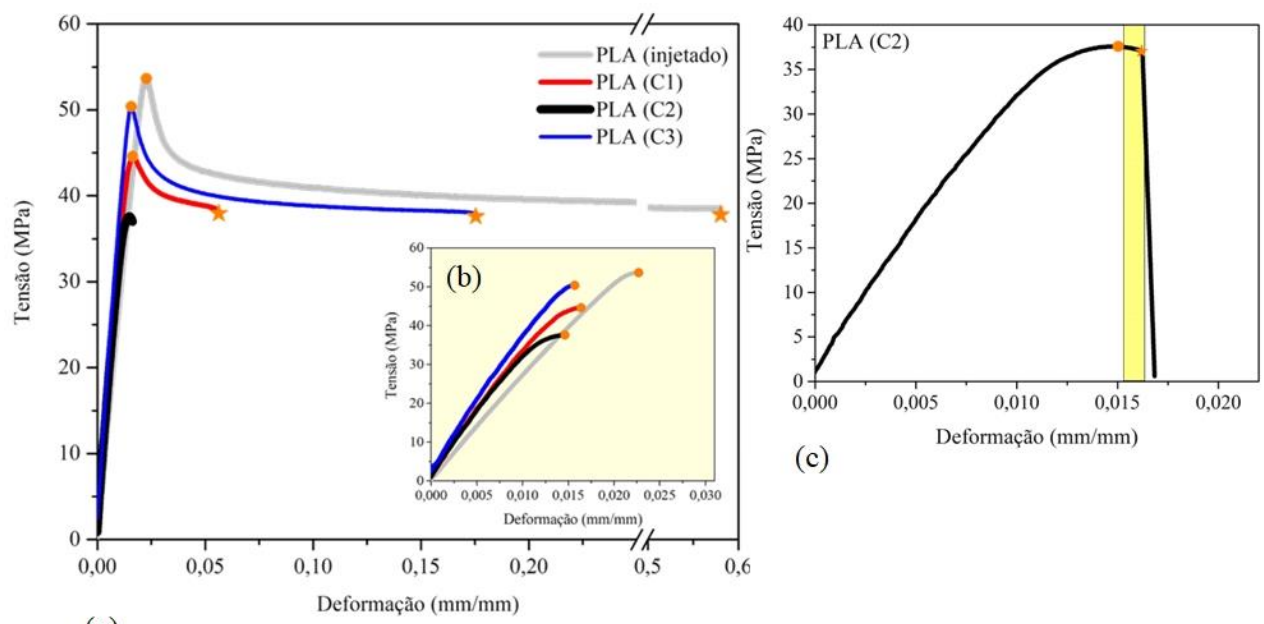

(a)

Figura 14: Curvas tensão deformação para as amostras em PLA (a), (b) zoom na porção elástica, e (c) amostra em C2.
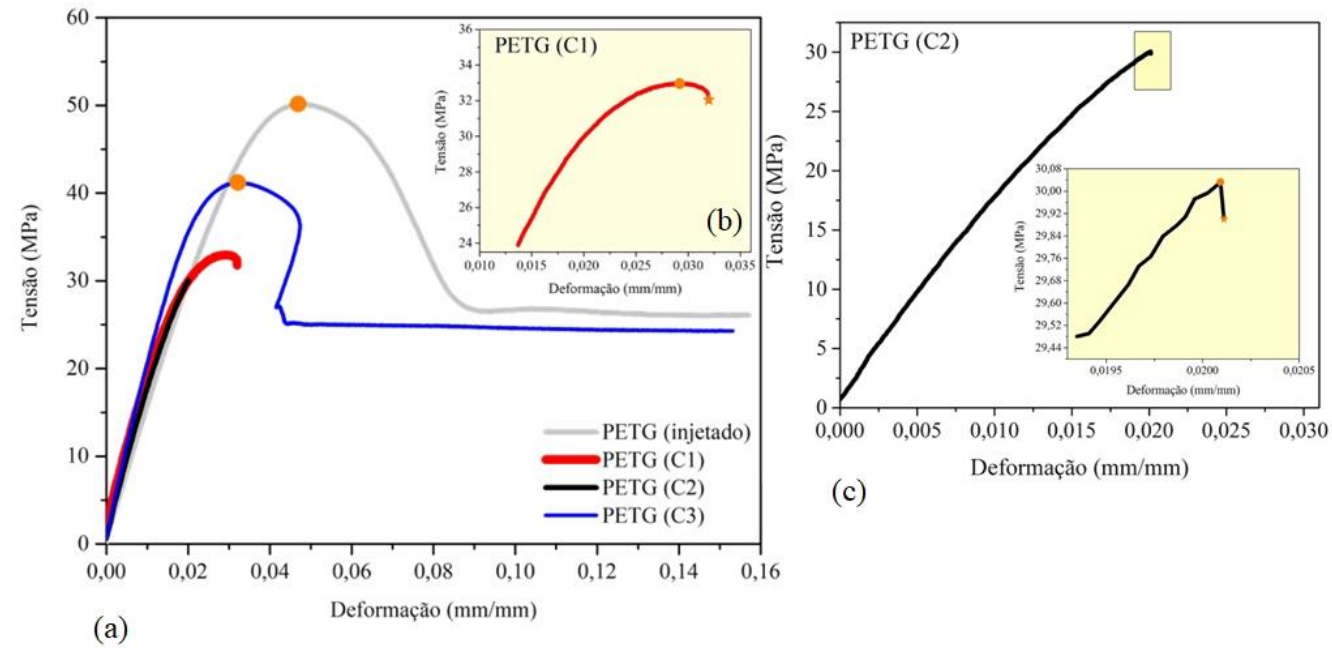

Figura 15: Curvas tensão deformação para as amostras em PETG (a), zoom na curva da amostra em C1 (b), e (c) amostra em $\mathrm{C} 2$.

Além da curva clássica que remete a um material frágil — Figuras 14 e 15 (c) —, outras evidências retratam este comportamento nas peças fabricadas com a configuração $0^{\circ} / 90^{\circ}(\mathrm{C} 2)$. Primeiramente tem-se os efeitos decorrentes da aplicação das cargas durante o ensaio mecânico, tais como o já mencionado "esbranquiçamento" das amostras. Esta característica, mais visível no PLA por ser um material pigmentado, também foi observada nas peças que apresentaram maiores módulos e deformações até a ruptura. Na Figura 16, é apresentada uma comparação (aproximada) entre as peças em PLA com as diferentes condições experimentais, em função da coloração na escala $\mathrm{CMYK}^{7}$. A peça fabricada com C3 apresentou um maior "esbranqui-

${ }^{7}$ Escala de cores formada por Ciano (C) (do original cyan, tons de azul), Magenta (M) (original de mesmo o nome, tons avermelhados), Amarelo (Y) (do original yellow), e Preto (K) (do original black, no qual "K" foi designada por ser a última letra da palavra, e "B" poderia confundir com blue) [90]. 
çamento", retratado pelo menor percentual de coloração azul (47\%), seguido pela Condição 1 (57\%). Já a amostra construída com C2 teve uma porcentagem de azul (71\%) muito próxima a de um componente não ensaiado mecanicamente $(73 \%)$, o que colabora para as discussões sobre a fragilidade realizadas anteriormente. Como segunda evidência para $\mathrm{C} 2$ tem-se uma fratura característica de material frágil ocorrida no ensaio de tração — Figura 17 (a) para o PLA e (b) para o PETG.

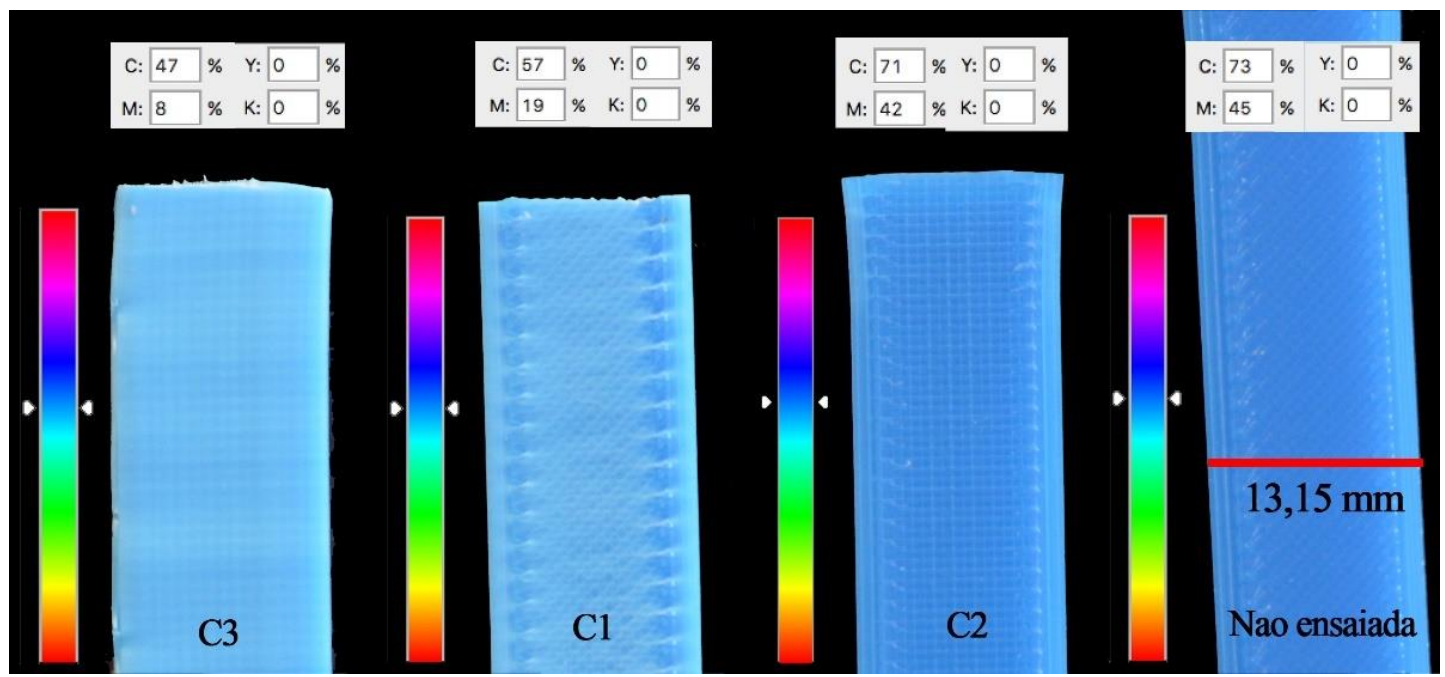

Figura 16: Efeito de "branqueamento" nas peças após a realização do ensaio de tração (escala cromática CMYK).

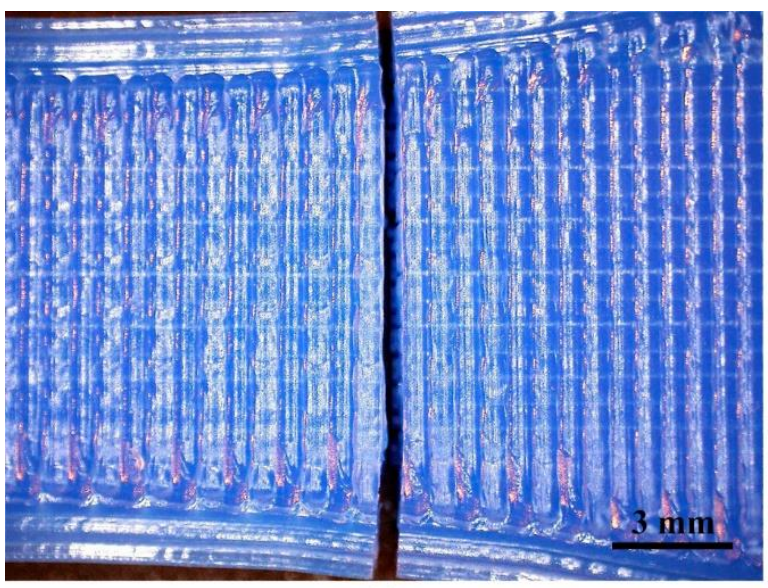

(a)

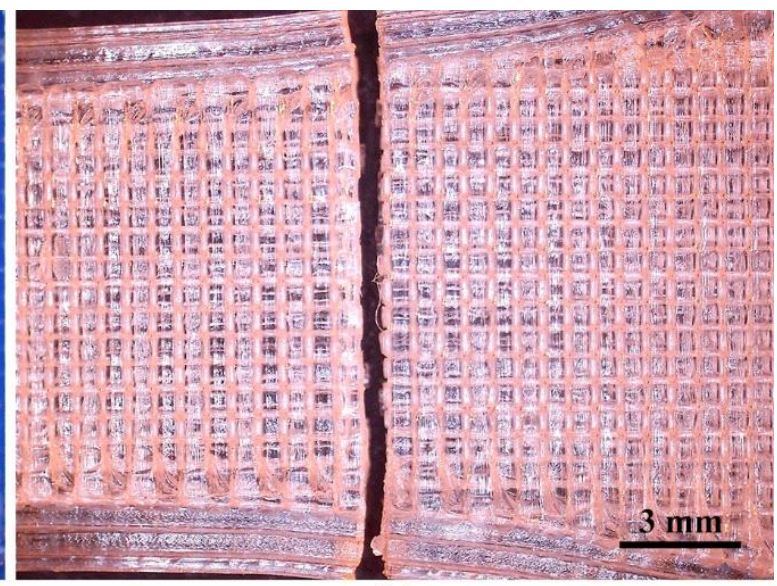

(b)

Figura 17: Fratura das amostras na Condição 2, (a) PLA e (b) PETG.

Ainda sobre a análise das fraturas, é possível verificar algumas diferenças entre o PLA e o PETG nas Condições 1 e 3. Em C1 o PETG - Figura 18 (a) — apresentou uma fratura majoritariamente em $45^{\circ}$, praticamente alinhada com a direção de deposição dos filamentos nas camadas $\left(45^{\circ} /-45^{\circ}\right)$, enquanto que no PLA ocorreu transversalmente a secção do corpo de prova — Figura 18 (b). 


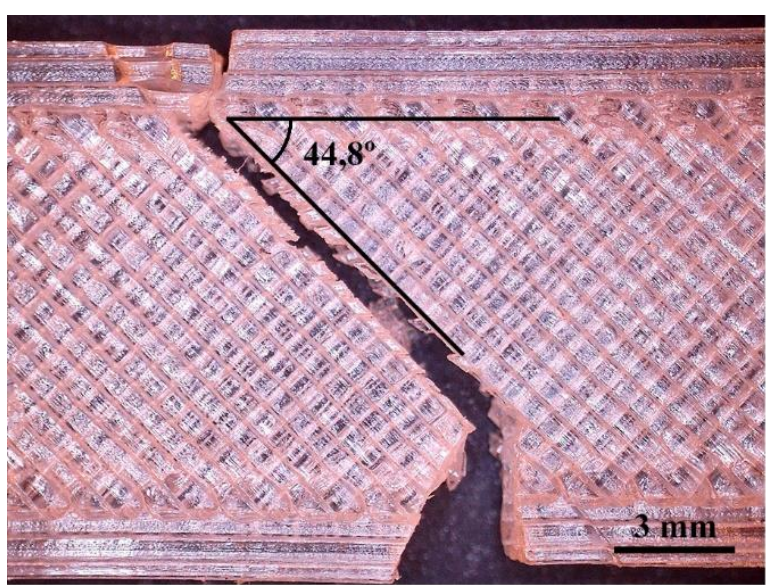

(a)

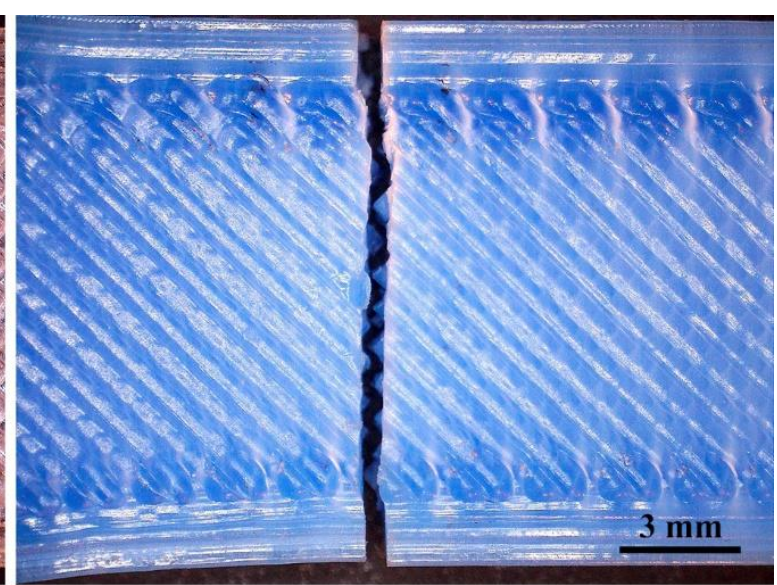

(b)

Figura 18: Fratura das amostras na Condição 1, (a) PLA e (b) PETG.

Para C3, o PLA apresentou uma fratura semelhante à ocorrida em C1, com uma característica de maior deformação (esticamento) dos filamentos individuais na região central do corpo de prova, Figura 19 (a). Já no PETG não ocorreu uma fratura momentos após atingir a tensão máxima, Figura 19 (b), o material permaneceu deformando ao longo dos filamentos unidirecionais, até que passado um intervalo de tempo o ensaio foi interrompido. Este efeito pode ser atribuído às macromoléculas na região amorfa dos polímeros que se entrelaçam vagamente e são fáceis de se espalhar e esticar, o que garante uma boa extensibilidade [91,92]. Como o PETG é um material amorfo, a propriedade descrita se intensificou na condição 3, motivada pelos filamentos unidirecionais. De forma a colaborar com os efeitos observados neste estudo, YANG et al. [91] verificaram fenômeno semelhante em seus experimentos. Ao contrário do material avaliado neste estudo, PETG (amorfo), os autores investigaram os efeitos da cristalização em peças fabricadas por Impressão 3D utilizando o polímero PEEK, com estrutura semicristalina. Entretanto, a correlação que pode ser feita entre os resultados é que YANG et al. [91] verificaram que na medida em que se reduzia o grau de cristalinidade do material, o alongamento até a ruptura aumentava, chegando a valores de deformação de até $130 \%$, atingindo maior plasticidade. Por outro lado, segundo os mesmos, se o grau de cristalinidade aumentava $20 \%$, o alongamento também reduzia $20 \%$.

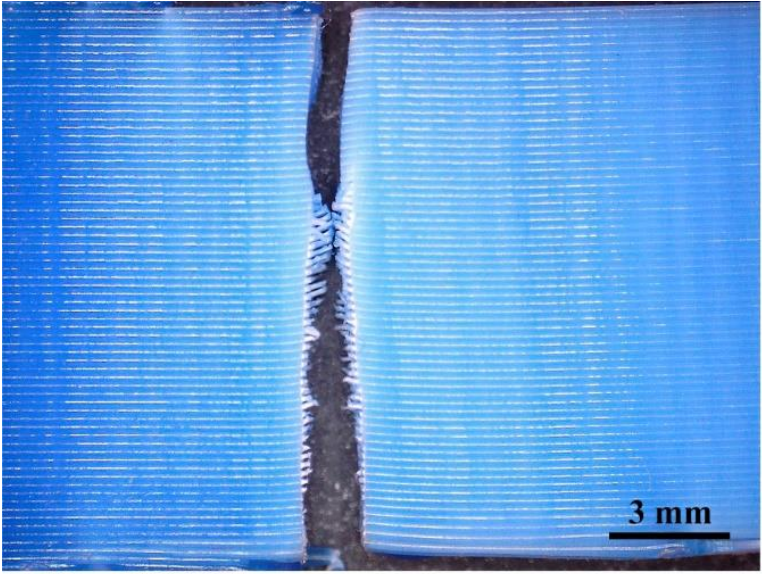

(a)

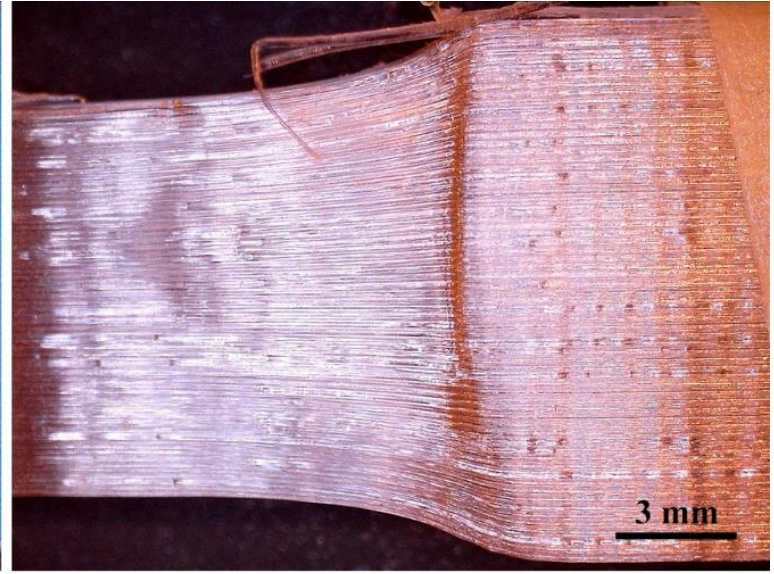

(b)

Figura 19: Fratura da amostra na Condição 3, (a) PLA e (b) comportamento do PETG.

Outra característica analisada nos ensaios de tração foi a deformação no ponto máximo da tensão Tabela 6 e Figura 12 (a). Sobre este aspecto algumas informações interessantes foram observadas. No PLA a condição com maior deformação até a tensão máxima foi a C1 com 1,7\%. Já as condições C2 e C3 apresentaram valores médios $(\approx 1,5 \%)$ estatisticamente iguais segundo os resultados da análise de Tukey. Em outras palavras, a condição com melhor aproveitamento em módulo e resistência máxima à tração apresentou uma 
deformação no ponto em análise igual a configuração que tornou as peças mais frágeis. No entanto, é importante ressaltar que no total, as peças em C3 deformaram-se cerca de $16 \%$ até a ruptura total, enquanto que em C2 apenas $2 \%$ (ou somente $0,5 \%$ a partir da deformação no extremo da tensão). Para o PETG, a maior deformação no pico máximo da tensão foi para as condições $\mathrm{C} 1$ e $\mathrm{C} 3(\approx 3 \%)$, ou seja, os dois conjuntos de dados apresentaram médias iguais. Assim como no caso do PLA, ao se comparar as deformações máximas verificou-se que a Condição 1 rompeu com aproximadamente 4,5\%, e C3 em algumas amostras a deformação chegou a $47 \%$, relembrando que o ensaio, nestes casos de altas deformações, foi interrompido antes da ruptura total das peças.

O PETG caracterizou-se como um material com maior capacidade de deformação até a tensão máxima, ou na zona elástica, quando comparado ao PLA; por outro lado, este, especialmente nas condições 1 e 2, deformou-se mais até a ruptura (zona plástica) que o PETG. Um dos motivos para este feito, pode ser o fato de os filamentos individuais de PLA suportarem maiores cargas que os de PETG. Em outras palavras, como nas condições 1 e 2 se tem menor quantidade de zonas de alta resistência, ou seja, filamentos individuais alinhados na direção de tração, no caso do PLA, estas poucas regiões existentes conseguem se deformar mais após atingirem o pico máximo da tensão (por serem mais resistentes) do que as do PETG. Quanto se tem a condição ótima, ou seja, que se aumenta a magnitude de força do PETG, condição 3, as propriedades do material quanto a deformação são ressaltadas, e este atinge maiores níveis de ductilidade em relação ao PLA.

Como última resposta avaliada, tem-se a medição da massa das amostras - Tabela 6 e Figura 12 (b). Para ambos os materiais a condição $1\left(45^{\circ}-45^{\circ}\right)$ foi a que apresentou maior massa, tendo as configurações 2 e 3 , de acordo com teste post hoc de Tukey, gerado grupos de amostras com massas médias iguais.

Diferentemente do estudo de TANIKELLA et al. [11], que concluiu que a resistência à tração de peças fabricadas por impressão 3D, em diversos materiais, incluindo o T-Glase ${ }^{\circledR}$ (nome comercial do PETG) ${ }^{8}$, depende em grande parte da massa das amostras, - com tendência de crescimento da resistência em função de maiores massas na maior parte dos filamentos — , neste estudo a relação não foi verificada — Figura 20 (a) e (b). Uma justificativa para este fato é que no presente artigo foram estudadas diferentes condições de fabricação das amostras (ângulos de varredura), que foram muito significativas para as variações nas respostas mecânicas, enquanto que no estudo de TANIKELLA et al. [11] foi usada apenas uma estratégia de construção (segundo os autores, diagonal à direção de aplicação da carga de tração), variando os materiais - ABS, Nylon, Policarbonato, HIPS (5 cores diferentes), e T-Glase ${ }^{\circledR}$ (5 cores diferentes). Em outras palavras, com base no contexto avaliado neste estudo, um aumento na quantidade de material depositado não tem, na maior parte dos casos, um impacto relevante no melhoramento das propriedades mecânicas. O que determina um aumento na qualidade das peças é a disposição dos filamentos depositados no interior das camadas (preferencialmente quando alinhados na direção das cargas aplicadas), a qualidade da união entre estes filamentos, e a uniformidade na formação dos vazios.

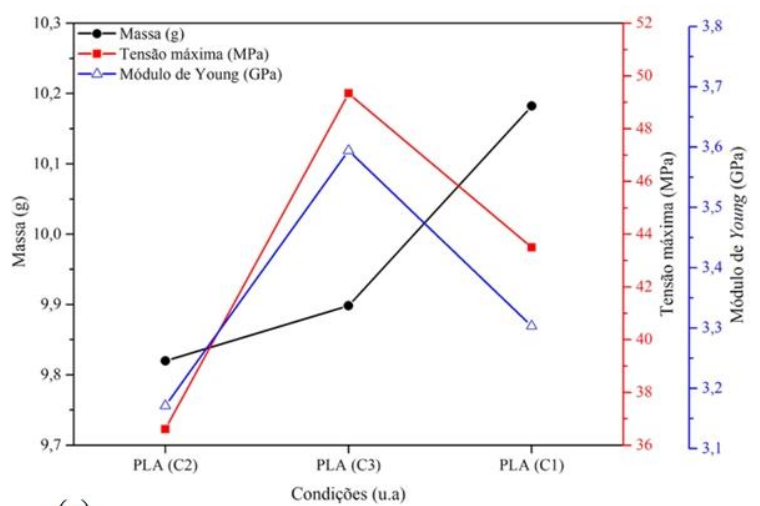

(a)

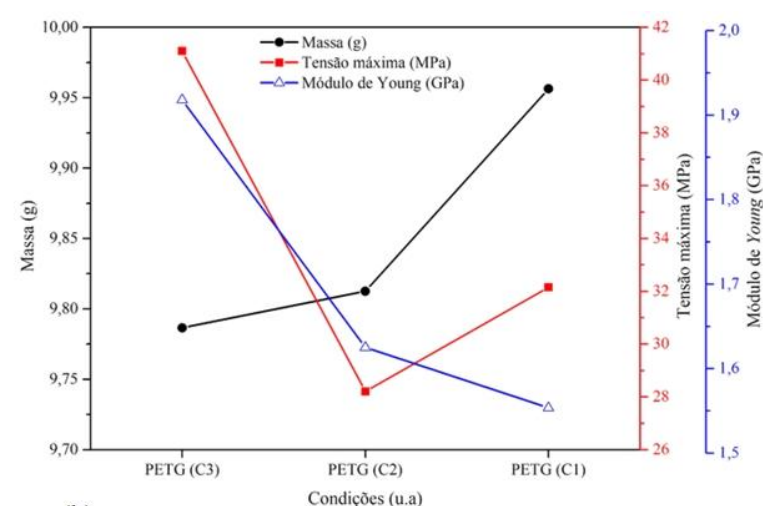

(b)

Figura 20: Massa versus tensão máxima e módulo de Young, (a) PLA e (b) PETG.

Concluídas as análises com os resultados das amostras impressas, verificou-se, assim como nas injetadas, uma superioridade do PLA em relação ao PETG na tensão máxima à tração e no módulo de Young. A exceção foi novamente a deformação na tensão máxima, na qual o PETG se destacou. Algumas comparações

\footnotetext{
${ }^{8}$ Nome comercial utilizado pela empresa Taulman $3 D$ para referir-se a sua formulação de PETG [93].
} 
entre as peças injetadas e as impressas podem ser feitas, Figura 21 (a) e (b). No PLA a diferença entre a tensão máxima das peças impressas diminuiu em relação às injetadas em cerca de $18 \%, 31 \%$, e 7,5\% nas Condições C1, C2 e C3, respectivamente. Já no PETG os percentuais de redução foram um pouco maiores, 35\%, $43 \%$ e $17 \%$, nesta ordem para C1, C2 e C3, o que pode ser entendido como maior resistência das peças injetadas do que as impressas para este material frente ao PLA.

Em relação ao módulo de Young verificou-se que as peças impressas apresentaram valores superiores aos componentes injetados. O módulo de elasticidade das amostras injetadas em PLA foi cerca de 19\%, 15\%, e $25 \%$, menor que os dos elementos impressos em C1, C2 e C3, respectivamente. Para o PETG a maior diferença entre o módulo das peças impressas em relação às injetadas foi identificado nos resultados da condição 3, aproximadamente 28\% superior. Diferentemente do PLA, nas condições C1 e C2 o módulo de Young das amostras em PETG foi apenas 3\% e 8\% maior que o das peças injetadas. Apesar dos testes de tração para os elementos impressos e injetados terem sido realizados em máquinas de ensaio diferentes, o que poderia influenciar nas questões relacionadas ao módulo de elasticidade - aperto e deslizamento das amostras nas garras, aspectos de medição de deformação pelo extensômetro-, os efeitos observados neste estudo (maior módulo de Young para as amostras impressas) também foram descritos nos estudos de SONG et al. [36] e PAGE et al. [37], os quais utilizaram o PLA, sustentando assim as descobertas realizadas.

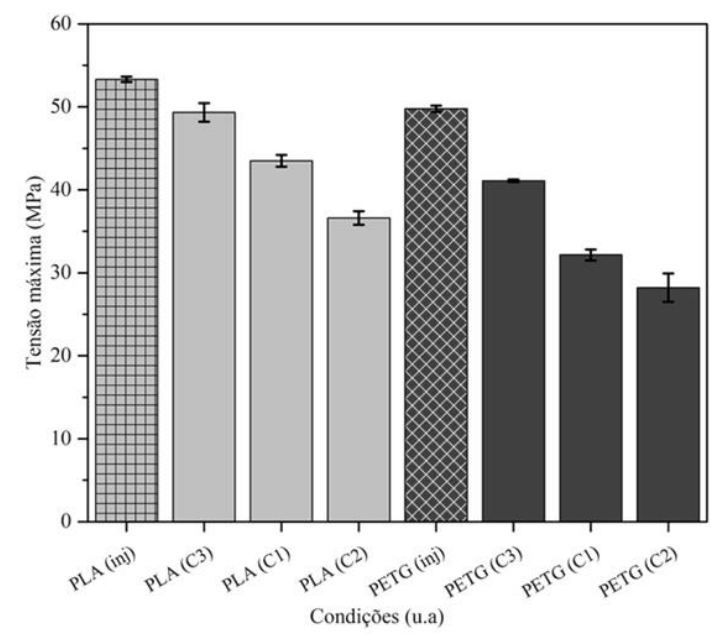

(a)

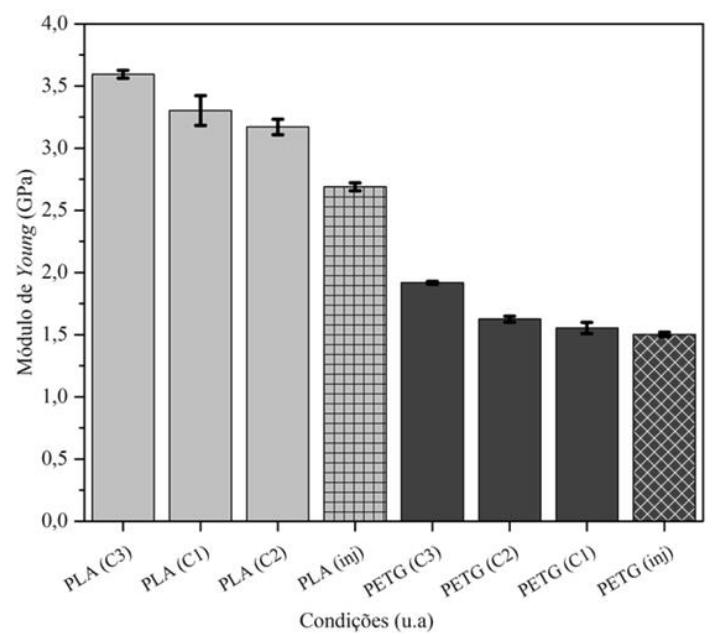

(b)

Figura 21: Comparação entre as respostas para peças injetadas e impressas, (a) tensão máxima e (b) módulo de Young.

Os melhores resultados para a tensão máxima observados nas peças injetadas se devem ao fato de que as cargas aplicadas no ensaio de tração se distribuem ao longo de uma massa uniforme e sólida, isto é, em uma estrutura interna livre de vazios. Além dos vazios, nas peças impressas as forças são suportadas basicamente por filamentos individuais, uma vez que entre estes existem linhas de união que se caracterizam por regiões fracas e que não suportam cargas, mesmo na configuração unidirecional (C3) que se obtiveram os melhores resultados.

A sensível diferença observada no grau de cristalinidade da peça em PLA injetada em relação à impressa, no sentido de crescimento, não foi um fator determinante para aumentar a rigidez (módulo de Young) destas, apesar de a literatura descrever que o módulo de elasticidade tende a aumentar conforme aumenta a cristalinidade [82]. Neste estudo as características naturais induzidas pelo processo de Impressão 3D (vazios e linhas de união) foram responsáveis por gerarem peças com baixa capacidade de deformação em resposta à aplicação de cargas, principalmente na porção elástica da curva tensão deformação (Figuras 14 e 15), quando comparadas às injetadas, o que colabora para o aumento do módulo de Young. Outras evidências encontradas no trabalho sustentam esta descoberta: (i) mesmo as peças impressas em condições (C1 e C2) que geraram menores valores de resistência máxima à tração e módulo de Young em comparação às amostras com melhores resultados (C3), e que não foram analisadas em relação à cristalinidade, apresentaram maior rigidez que as amostras injetadas; e (ii) mesmo no PETG, que é um material amorfo e, portanto, não dispõe de efeitos de cristalização, as peças impressas apresentaram um comportamento de superioridade na rigidez em comparação aos componentes injetados com o mesmo material. 
Por fim, as análises químicas (FTIR) mostraram que a estrutura molecular dos polímeros não foi alterada pelos processos de fabricação aos quais os materiais foram submetidos. Portanto, colaboram para a constatação de que as diferenças no comportamento mecânico das peças impressas e injetadas são decorrentes de efeitos das tecnologias na qualidade estrutural (sobre o aspecto construtivo) das peças obtidas.

\section{CONCLUSÕES}

A caracterização do PETG permitiu verificar que as propriedades térmicas, químicas e mecânicas do filamento eram semelhantes às deste material quando aplicado a outros contextos, que não especialmente a Manufatura Aditiva. Assim se atingiu o objetivo principal deste estudo, fornecer informações relevantes sobre o material de recente adoção no contexto abordado. As mesmas considerações podem ser feitas quanto ao PLA. Os benefícios do estudo para os usuários da tecnologia podem ser resumidos em: (i) melhoramento da configuração dos parâmetros de processo de Impressão 3D; (ii) base para desenvolvimento e comparação entre estudos na área de caracterização de materiais; (iii) informações para o projeto e desenvolvimento de peças funcionais, além do processo de seleção dos materiais; (iv) aplicação de referências generalistas dos polímeros no contexto da Manufatura Aditiva; (v) reconhecimento da qualidade dos materiais dos fornecedores, quando comparados aos descritos na literatura.

Comparativamente, o PLA mostrou-se um material mais resistente e rígido que o PETG, tanto nas peças impressas quanto nos corpos de prova injetados. O PLA, na melhor condição de impressão (C3), apresentou maior proximidade aos valores de tensão máxima obtidos nas peças injetadas. Esta mesma condição gerou resultados de tensão máxima estatisticamente semelhantes aos do PETG injetado. Por outro lado, o PETG apresenta algumas vantagens em relação ao PLA: (i) maior resistência a degradação térmica, (ii) tendência a maior estabilidade térmica, visto que seu comportamento térmico foi pouco afetado pelas variáveis envolvidas nos processos de fabricação aos quais foram submetidos neste trabalho; (iii) na maior parte das respostas avaliadas neste estudo, o PETG apresentou menor dispersão estatística que o PLA; (iv) a flexibilidade apresentada pelo PETG o torna interessante, principalmente na Impressão 3D, para aplicações que necessitam desta característica, como por exemplo, a construção de conexões do tipo snap-fits, em oposição ao PLA que é muito mais rígido.

Por fim, os resultados encontrados retratam a evolução da Impressão 3D baseada em extrusão, motivada pelo surgimento dos sistemas de código aberto e das máquinas de baixo custo, que permitiram que o processo e suas variáveis (parâmetros, equipamentos, softwares, materiais) pudessem ser estudados por uma vasta gama de especialistas e entusiastas, e assim encontrar soluções para melhorar a qualidade dos produtos gerados e direcionar a tecnologia para caminhos de aplicação final. Dentre as colaborações deste estudo, além de trazer mais informações sobre os materiais, mostrou-se ser possível alcançar resistências mecânicas à tração com valores de $69 \%$ a $93 \%$ das fornecidas por componentes injetados em PLA, e de $65 \%$ a $83 \%$ no PETG, através do ajuste dos parâmetros de processo, valores equiparáveis ou mesmo superiores aos apresentados na publicação de Ahn et al. [88], 65\% a 73\%, no ano de 2002. Busca-se ainda alertar os usuários sobre a importância do planejamento da construção das peças impressas, uma vez que as características mesoestruturais foram altamente significativas para a determinação do comportamento dúctil-frágil e das propriedades mecânicas gerais das peças impressas.

\section{AGRADECIMENTOS}

Ao Conselho Nacional de Desenvolvimento Científico e Tecnológico, CNPq, pelo financiamento da pesquisa de doutorado da qual este artigo faz parte, pelo programa Ciência sem Fronteiras, à Faculdade de Engenharia da Universidade do Porto (FEUP) e ao Instituto Federal de Santa Catarina (IFSC - Florianópolis). Ao projeto NORTE-01-0145-FEDER-000022 - SciTech - Science and Technology for Competitive and Sustainable Industries, cofinanciado pelo Programa Operacional Regional do Norte (NORTE2020), através do Fundo Europeu de Desenvolvimento Regional (FEDER).

\section{BIBLIOGRAFIA}

[1] AMBROSI, A., PUMERA, M., “3D-printing technologies for electrochemical applications”, Chemical Society Reviews, v. 45, n.10, pp. 2740-2755, Apr. 2016. 
[2] GEBHARDT, A., Understanding additive manufacturing, Munich, Hanser Publishers, 2011.

[3] DAVIM, J. P., Machining: fundamentals and recent advances, London, Springer-Verlag, 2008.

[4] SONG, C., LIN, F., BA, Z., et al., "My smartphone knows what you print: exploring smartphone-based side-channel attacks against 3D printers", In: Proceedings of the 2016 ACM SIGSAC Conference on Computer and Communications Security, pp. 895-907, Vienna, Oct. 2016.

[5] WOJTYLA, S., KLAMA, P., BARAN, T., "Is 3D printing safe? Analysis of the thermal treatment of thermoplastics: ABS, PLA, PET, and nylon", Journal of occupational and environmental hygiene, v.14, n.6, pp. 80-85, Jun. 2017.

[6] GIBSON, I., ROSEN, D., STUCKER, B., Additive manufacturing technologies: 3D printing, rapid prototyping, and direct digital manufacturing, 2 ed., New York, Springer, 2015.

[7] KOUSIATZA, C., KARALEKAS, D., "In-situ monitoring of strain and temperature distributions during fused deposition modeling process", Materials and Design, v. 97, n. 5, pp. 400-406, May. 2016.

[8] CHAN, K., COEN, M., HARDIK, J., et al., "Low-cost 3D printers enable high-quality and automated sample preparation and molecular detection", PloS one, v. 11, n. 6, e0158502, Jun. 2016.

[9] CASAVOLA, C., CAZZATO, A., MORAMARCO, V., et al., "Residual stress measurement in Fused Deposition Modelling parts", Polymer Testing, v.58, pp. 249-255, Jan. 2017.

[10] CICALA, G., LATTERI, A., DEL CURTO, B., et al., "Engineering thermoplastic for addtive manufacturing: a critical perspective with experimental evidence to support functional applications", Journal of Applied Biomaterials \& Functional Materials, v.15, n.1, e10-e18, Jan. 2017.

[11] TANIKELLA, N. G., WITTBRODT, B., PEARCE, J. M., "Tensile strength of commercial polymer materials for fused filament fabrication 3D printing", Additive Manufacturing, v. 15, pp. 40-47, Mar. 2017.

[12] BARNATT, C., 3D printing, 2 ed., England, Explainingthefuture.com, 2014.

[13] ARAÚJO, J. P., AGRAWAL, P., MÉLO, T. J. A., "Blendas PLA/PEgAA: avaliação da reatividade entre os polímeros e da concentração de PEgAA nas propriedades e na morfologia", Revista Eletrônica de Materiais e Processos, v.10, n. 3, pp. 118-127, Aug. 2015.

[14] CARRASCO, F., PAGÈS, P., GÁMEZ-PÉREZ, J., et al., "Processing of poly(lactic acid): characterization of chemical structure, thermal and mechanical properties", Polymer Degradation and Stability, v. 95, n.2, pp. 116-125, Feb. 2010.

[15] CEREGATTI, T., PECHARKI, P., PACHEKOSKI, W.M., et al., "Electrical and thermal properties of PLA/CNT composite films", Revista Matéria, v. 22, n. 3, e11863, Mar. 2017.

[16] CASTRO-AGUIRRE, E., IÑIGUEZ-FRANCO, F., SAMSUDI, H., et al., "Poly(lactic acid) - mass production, processing, industrial application, and end of life", Advances Drug Delivery Reviews, v. 107, pp. 333-366, Dec. 2016.

[17] GAIHONG, W., SHUQIANG, L., HUSHENG, J., et al., "Preparation and properties of heat resistant Polylactic acid (PLA)/Nano-SiO 2 composite filament", Journal of Wuhan University of Technology-Mater. Sci. Ed., v. 31, n. 1, pp. 164-171, Feb. 2016.

[18] WANG, M., WU, Y., LI, Y.D., et al., "Progress in toughening Poly(Lactic Acid) with renewable polymers", Polymer Review, v. 57, n. 4, pp. 557-593, Feb.2017.

[19] GARLOTTA, D., "A literature review of Poly(Lactic Acid)", Journal of Polymers and the Environment, v.9, n.2, pp. 63-84, Apr. 2001.

[20] MENG, B., DENG, J., QING, L., et al., "Transparent and ductile poly(lactic acid)/ poly(butyl acrylate) (PBA) blends: structure and properties", European Polymer Journal, v. 48, n.1 , pp. 127-135, Jan. 2012.

[21] AHMED, J., "Thermal properties of polylactides and stereocomplex", In: Ahmed, J., Rahman, M.S., Roos, Y.H., "Glass Transition and Phase Transitions in Food and Biological Materials", 1 ed., chapter 12, Chichester, UK; Hoboken, NJ, John Wiley \& Sons, 2017.

[22] ALSSABBAGH, M., TAJUDDIN, A. A., ABDULMANAP, M., et al., "Evaluation of 3D printing materials for fabrication of a novel multi-functional 3D thyroid phantom for medical dosimetry and image quality", Radiation Physics and Chemistry, v. 135, pp. 106-112, Jun. 2017.

[23] BAI, H., XIU, H, GAO, J., et al., "Tailoring impact toughness of poly(L-lactide)/poly( $\varepsilon$-caprolactone) (PLLA/PCL) blends by controlling crystallization of PLLA matrix", Applied Materials \& Interfaces, v.4, n.2, pp. 897-905, Feb. 2012. 
[24] KUMAR, M., MOHANTY, S., NAYAK, S.K., et al., "Effect of glycidyl methacrylate (GMA) on the thermal, mechanical and morphological property of biodegradable PLA/PBAT blend and its nanocomposites", Bioresource Technology, v. 101, n.21, pp. 8406-8415, Nov. 2010.

[25] Anatol Locker, ALL3DP, https://all3dp.com/1/petg-filament-3d-printing/ . Acessado em dezembro de 2017.

[26] MatterHackers, MATTERHACKERS, https://www.matterhackers.com/news/how-to-succeed-whenprinting-with-petg-filament . Acessado em dezembro de 2017.

[27] ALZAHRANI, M., Modification of recycled poly(ethylene terephthalate) for FDM 3D-printing applications, Tese de M.Sc, University of Waterloo, Waterloo, Ontario, Canada, 2017.

[28] WANG, X., LIU, W., ZHOU, H., et al., "Study on the effect of dispersion phase morphology on porous structure of poly (lactic acid)/poly (ethylene terephthalate glycol-modified) blending foams", Polymer, v. 54, n. 21, pp. 5839-5851, Oct. 2013.

[29] LAM, K. L., BAKAR, A. A., ISHAK, A. M., et al., “Amorphous copolyester/ polyoxymethylene blends: thermal, mechanical and morphological properties”, KGK Kautschuk Gummi Kunststoffe, v.57, n.11, pp. 570-578, Nov. 2004.

[30] FOCKE, W.W., JOSEPH, S., GRIMBEEK, J., et al., "Mechanical properties or ternary blends of ABS+HIPS+PETG”, Polymer Plastics Technology and Engineering, v. 48, n. 8, pp. 814-820, Jul. 2009.

[31] ALBUQUERQUE, A. J., “Optimización y caracterización de piezas de PLA fabricadas mediante técnicas aditivas”, TCC, Universidad Carlos III de Madrid, Madrid, 2014.

[32] SZYKIEDANS, K., CREDO, W., OSIŃSKI, D., "Selected mechanical properties of PETG 3-D prints", Procedia Engineering, v.177, pp. 455-461, Mar. 2017.

[33] SZYKIEDANS, K., CREDO, W., "Mechanical properties of FDM and SLA low-cost 3-D prints", Procedia Engineering, v.136, pp. 257-262, Feb. 2016.

[34] SANTANA, L., AHRENS, C.H., SABINO NETTO, A.C., et al., “Avaliação da composição química e das características térmicas de filamentos de PLA para impressoras 3D de código aberto", In: IX Congresso Nacional de Engenharia Mecânica, Fortaleza, Ceará, Brasil, 21 a 25 de Agosto de 2016.

[35] CUIFFO, M.A., SNYDER, J., ELLIOTT, A. M., et al., "Impact of the fused deposition (FDM) printing process on polylactic acid (PLA) chemistry and structure”, Applied Sciences, v.7, n.6, p. 579, Jun. 2017.

[36] SONG, Y., LI, Y., SONG, W., et al., "Measurements of the mechanical response of unidirectional 3Dprinted PLA", Materials and Design, v. 123, pp. 154-164, Jun. 2017.

[37] PAGE, C., KREUZER, S., ANSARI, F., et al., “Optimizing 3D printed components: a methodological approach to assessing print parameters on tensile properties", In: Proceedings of ANTEC ${ }^{\circledR} 2017$, pp. 82-88, Anaheim, May. 2017.

[38] WANG L., GRAMLICH, W., M., GARDNER, D. J., "Improving the impact strength of Poly(lactic acid) (PLA) in fused layer modeling (FLM)", Polymer, v. 114, pp. 242-248, Apr. 2017.

[39] SABINO NETTO, A. C., SANTANA, L., PEREIRA, I., et al., "Avaliação de corpos de prova produzidos em PLA por manufatura aditiva por extrusão e moldagem por injeção", In: $13^{\circ}$ Congresso Iberoamericano de Engenharia Mecânica, Lisboa, Portugal, 23 a 26 de Outubro de 2017.

[40] SCAPINI, P., Morfologia e propriedades térmicas de compósitos de HDPE/EVA com POSS, Tese de M.Sc, Universidade de Caxias do Sul, Caxias do Sul, RS, Brasil, 2008.

[41] FISHER, E. W., STERZEL, H. J., WEGNER, G., "Investigation or the structure of solution grown crystals of lactide copolymers by means of chemical reactions", Kolloid-Zeitschrift und Zeitschrift für Polymere, v. 251, n. 11, pp. 980-990, Nov. 1973.

[42] ZHAI, W., KO, Y., ZHUU, W., et al., "A study of the crystallization, melting, and foaming behaviors of polylactic acid in compressed $\mathrm{CO}_{2}$ ", International Journal of Molecular Science, v. 10, n. 12, pp. 53815397, Dec. 2009.

[43] RODRIGUEZ, J.F., THOMAS, J.P., RENAULD, J. E., "Characterization of the mesostructure of fuseddeposition acrylonitrile-butadiene- styrene materials”, Rapid Prototyping Journal, v. 6, n. 3, pp. 175-185, 2000 .

[44] TURNER, B. N., STRONG, R., GOLD, S. A., “A review of melt extrusion additive manufacturing processes: I. process design and modeling”, Rapid Prototyping Journal, v. 20, n.3, pp 192-204, 2014. 
[45] ALAIMO, G., MARCONI, S., COSTATO, L., et al., "Influence of meso-structure and chemical composition on FDM 3D-printed parts", Composites Part B, v. 113, pp. 371-380, Mar. 2017.

[46] ASTM, Standard tests method for tensile properties of plastics, United States, ASTM International, 2010.

[47] MOHAMED, O. A., MASOOD, S. H., BHOWMIK, J. L., "Optimization of fused deposition modeling process parameters: a review of current research and future prospects", Advances in Manufacturing, v.3, n. 1, pp. 42-53, Mar. 2015.

[48] CARNEIRO, O. S., SILVA, A. F., GOMES, R., "Fused deposition modeling with polypropylene", $M a-$ terials and Design, v. 83, pp. 768-776, Oct. 2015.

[49] SOOD, A. K., OHDAR, R. K., MAHAPATRA, S. S., "Experimental investigation and empirical modelling of FDM process for compressive strength improvement", Journal of Advanced Research, v. 3. n.1, pp. 81-90, Jan. 2012.

[50] LIMA, M. V. A., Modelo de fatiamento adaptativo para prototipagem rápida - implementação no processo de modelagem por fusão e deposição (FDM), Tese de M.Sc., Universidade Tecnológica Federal do Paraná, Curitiba, PR, Brasil, 2009.

[51] BRATL, M., Customizable personal manufacturing, Tese de M.Sc., Fachhochschule Der Wirtschaft, Hannover, Alemanha, 2013.

[52] DOMINGO-SPIN, M., BORROS, S., AGUILLO, N., et al., "Influence of building parameters on the dynamic mechanical properties of polycarbonate fused deposition modeling parts", 3D Printing and Additive Manufacturing, v. 1, n.2, pp. 70-77, Jun. 2014.

[53] SHIH, Y. F., HUNAG, C. C., "Polylactic acid (PLA)/banana fiber (BF) biodegradable green composites", Journal of Polymer Research, v. 18, n. 6, pp. 2335-2340, Nov. 2011.

[54] CARRASCO, F., PAGÈS, P., GÁMES-PÉREZ, J., et al., "Kinetics of the thermal decomposition of processed poly (lactic acid)", Polymer Degradation and Stability, v. 95, n. 12, pp. 2508-2514, Dec. 2010.

[55] CHEN, T., JIANG, G., LI, G., et al., "Poly(ethylene glycol-co-1,4-cyclohexanedimethanol terephthalate) random copolymers: effect of copolymer composition and microstructure on thermal properties and crystallization behavior", RSC Advances, v.5, n.74, pp. 60570-60580, Jul.2015.

[56] PASZKIEWICZ, S., SZYMCZYK, A., PAWLIKOWSKA, D., et al., "Synthesis and characterization of poly(ethylene terephthalate-co-1,4-cyclohexanedimethylene terephtlatate)-block-poly(tetramethylene oxide) copolymers", RSC Advances, v.7, n.66, pp. 41745-41754, Aug. 2017.

[57] CHIENG, B.W., IBRAHIM, N.A., THEN, Y.Y., et al., "Epoxidized vegetable oils plasticized poly(lactic acid) biocomposites: mechanical, thermal and morphology properties", Molecules, v.19, n.10, pp. 16024-16038, Oct. 2014.

[58] KUMAR, A., RAO, T.V., CHOWDHURY, S.R., et al., "Compatibility confirmation and refinement of thermal and mechanical properties of poly(lactic acid)/poly(ethylene-co-glycidyl methacrylate) blend reinforced by hexagonal boron nitride", Reactive and Functional Polymers, v.117, pp.1-9, May. 2017.

[59] CHOKSI, N., DESAI, H., "Synthesis of biodegradable polylactic acid polymer by using lactic acid monomer", International Journal of Applied Chemistry, v.13, n.2, pp. 377-384, 2017.

[60] MAI, T.T.T., NGUYEN, T.T.T, LE, Q.D., et al., "A novel nanofiber Cur-loaded polylactic acid constructed by electrospinning", Advances in Natural Sciences: Nanoscience and Nanotechnology, v.3, n.2, 025014 (4pp), May. 2012.

[61] HAMI, Z., AMINI, M., GHAZI-KHANSARI, M., et al., "Doxorubicin-conjugated PLA-PEG-Folate based polymeric micelle for tumor-targeted delivery: synthesis and in vitro evaluation", DARU Journal of Pharmaceutical Sciences, v.22, n.30, Mar. 2014.

[62] YUNIARTO, K., PURWANTO, Y.A., PURWANTO, S., et al., "Infrared and Raman studies on polylactide acid and polyethylene glycol-400 blend", In: AIP Conference Proceedings 1725, The $3^{\text {rd }}$ International Conference on Advanced Materials Science and Technology, 020101-1 - 020101-6, 2016.

[63] SHARIFAH, I.S.S, QAIROL, A.A.B., AZLINA, H.N., et al., "Thermal, structural and mechanical properties of Melt Drawn load poly(lactic acid) fibers", In: Procedia Engineering, Advances in Material \& Processing Technologies Conference, v.184, pp. 544-551, May. 2017. 
[64] BITENCOURT, S.S., BATISTA, K.C., ZATTERA, A.J., et al., "Desenvolvimento de biocompósitos de poli(L-ácido láctico) (PLLA) com serragem de madeira", Matéria (R.J.), v.22, n.4, Ago. 2017.

[65] HILAL, N., ISMAIL, A.F., WRIGHT, C.J., Membrane fabrication, Boca Raton, CRC Press Taylor \& Francis Group, 2015.

[66] NANTHANANON, P., SEADAN, M., PIVSA-ART, S., et al., "Enhanced crystallization of poly (lactic acid) through reactive aliphatic bisamide", In: IOP Conference Series: Materials Science and Engineering, 2015 Global Conference on Polymer and Composite Materials, v.87 012067, Beijing, 2015.

[67] KACZMAREK, H., VUKOVIĆ-KWIATKOWSKA, I., "Preparation and characterization of interpenetrating networks based on polyacrylates and poly(lactic acid)", eXPRESS Polymer Letters, v.6, n.1, pp. 78-94, Aug. 2011.

[68] CAI, Y., JUNJANG, Lv., JIMING, F., "Spectral characterization of four kinds of biodegradable plastics: poly(lactic acid), poly(butylenes adipate-co-terephthalate), poly(hydroxybutyrate-co-hydroxyvalerate) and poly(butylenes scuccinate) with FTIR and Raman Spectroscopy", Journal of Polymers and the Environment, v.21, n.1, pp. 108-114, Mar.2013.

[69] KISTER, G., CASSANAS, G., VERT, M., "Effects of morphology, conformation and configuration on the IR and Raman spectra of various poly(lactic acid)s", Polymer, v.39, n.2, pp.267-273, Jun.1998.

[70] XU, R., XIE, J., LEI, C., "Influence of melt-draw ratio on the crystalline behavior of a polylactic acid cast film with a chi structure", RSC Advances, v.7, n.3, pp.39914-39921, Aug.2017.

[71] JAYAKUMAR, R., RAJKUMAR, M., NAGENDRAN, R., et al., "Synthesis and characterization of metal-containing polyurethanes with antibacterial activity", Journal of Applied Polymer Science, v.85, n.6, pp. 1194-1206, May.2002.

[72] STRAIN, I.N., WU, Q., POURRAHIMI, A.M., et al., "Electrospinning of recycled PET to generate tough mesomorphic fibre membranes for smoke filtration", Journal of Materials Chemistry A, v.3, n.4, pp. 1632-1640, 2015.

[73] CHEN, T., ZHANG, W., ZHANG, J., "Alkali resistance of poly(ethylene terephthalate) (PET) and poly(ethylene glycol-co-1,4-cyclohexanedimethanol terephthalate) (PETG) copolyesters: The role of composition", Polymer Degradation and Stability, v.120, pp. 232-243, Jul. 2015.

[74] CHEN, C., ZHANG, J., "Surface hydrophilic modification of acrylonitrile-butadiene-styrene terpolymer by poly(ethylene glycol-co-1,4-cyclohexanedimethanol terephthalate): Preparation, characterization, and properties studies", Applied Surface Science, v.388, part A, pp. 133-140, Mar. 2016.

[75] NAKAMURA, H., SAKAI, H., AOSHIMA, S., et al., "Formation of triangular polymer domains in surface films adsorbed on solid substrate", Journal of Oleo Science, v.51, n.12, pp. 781-787, 2002.

[76] LEE, S.W., HUH, W., HONG, Y.S, et al., "Synthesis and thermal properties of poly(cyclohexylene dimethylene terephthalate-co-butylene terephthalate", Korea Polymer Journal, v.8, n.6, pp. 261-267. 2000.

[77] GUO, R.H., JIANG, S.Q., YUEN, C.W.M., et al.., "Microstructure and electromagnetic interface shielding effectiveness of electrodes Ni-P plated polyester fabric", Journal of Materials Science: Materials in Electronics, v.20, n.8, pp. 735-740, 2009.

[78] COLE, K.C., AJJI, A., PELLERIN, É., "New insights into the development of ordered structure in poly(ethylene terephthalate). 1. Results from external reflection infrared spectroscopy", Macromolecules, v.35, n.3, pp. 770-784, Jan. 2002.

[79] WARD, I.M., WILDING, M.A., "Infra-red and Raman spectra of poly $(m$-methylene terephthalate) polymers", v.18, n.4, pp. 327-335, 1977.

[80] COLE, K.C., GUÈVREMONT, J., AJJI, A., et al., "Characterization of surface orientation in poly(ethylene terephthalate) by front-surface reflection infrared spectroscopy", Applied Spectroscopy, v.48, n.12, pp. 1513-1521, 1994.

[81] SAFAK, S., KARACA, E., "Production and characterization of poly(ethylene terephthalate) nanofibrous mat including tourmaline additive", Textile Research Journal, v.86, n.15, pp. 1651-1658, 2016.

[82] CANEVAROLO, S. V. J., Ciência dos polímeros: um texto básico para tecnólogos e engenheiros, 2 ed., São Paulo, Artliber Editora, 2006. 
[83] CARVALHO, M. P., Análise de tensões e deformações em estruturas termoplásticas usando o método de elementos finitos, Tese de M.Sc, Pontifícia Universidade Católica do Rio Grande do Sul, Porto Alegre, RS, Brasil, 2007.

[84] HERNANDEZ, R. J. "Polymer properties", In: Yam, K. L., (editor), The Wiley Encyclopedia of Packaging Technology, 3 ed., chapter P, United States of America, John Wiley \& Sons, 2009.

[85] KATZ, H.S., MILEWSKI, J. V., Handbook of fillers for plastics, New York, Van Nostrand Reinhold, 1987.

[86] BANIK, K., Process-induced long-term deformation behavior of injection molded semicrystalline thermoplastics, Tese de M.Sc, Chemnitz University of Technology, Alemanha, 2006.

[87] HENTON, D. E., GRUBER, P., LUNT, J., et al., "Polylactic acid technology", In: Mohanty, A. K., Misra, M., Drzal,L. T. (eds), Natural Fibers, Biopolymers, and Biocomposites, chapter 16, Boca Raton, CRC Press Taylor \& Francis Group, 2005.

[88] AHN, S. H., MONTERO, M., ODELL, D., et al., "Anisotropic material properties of fused deposition modeling ABS", Rapid Prototyping Journal, v.8, n.14, pp. 248-257, 2002.

[89] BELLINI, A., GÜÇERI, S., "Mechanical characterization of parts fabricated using fused deposition modeling", Rapid Prototyping Journal, v.9, n.4, pp. 252-264, 2003.

[90] GALER, M., HORVAT, L., Digital imaging: essential skills, 3 ed., Burlington, Focal Press, 2005.

[91] YANG, C., TIAN, X., LI, D., et al., "Influence of thermal processing conditions in 3D printing on the crystallinity and mechanical properties of PEEK material", Journal of Materials Processing Technology, v. 248, pp. 1-7, Oct. 2017.

[92] MARK, J. E., Physical properties of polymers handbook, 2 ed., New York, Springer Science + Business Media LLC, 2007.

[93] AIRWOLF 3D, https://airwolf3d.com/2015/02/25/t-glase-and-petg/ . Acessado em novembro de 2017. 


\section{ANEXO}

Os resultados da análise de comparação de médias pelo método de Tukey são apresentados na Tabela 8.

Tabela 8: Resultados da análise de Tukey.

\begin{tabular}{l|c|c|c|c}
\hline \multirow{2}{*}{ DIFERENÇA } & TESTE DE TUKEY - PLA MÓDULO DE YOUNG (GPa) \\
\cline { 2 - 5 } & DIF.ENTRE MÉDIAS & EP & IC DE 95\% & VALOR P \\
\hline C1 - C2 & 0,13 & 0,05 & $(-0,003 ; 0,268)$ & 0,06 \\
\hline C3 - C2 & 0,42 & 0,05 & $(0,288 ; 0,559)$ & 0,00 \\
\hline C3 - C1 & 0,29 & 0,05 & $(0,156 ; 0,456)$ & 0,00 \\
\hline DIFERENÇA & TESTE DE TUKEY - PLA DEFORMAÇÃO NA TENSÃO MÁX. (mm/mm) \\
\hline C1 - C2 & 0,0018 & 0,0002 & $(0,0012 ; 0,0025)$ & 0,00 \\
\hline C3 - C2 & 0,0004 & 0,0002 & $(-0,0002 ; 0,0010)$ & 0,28 \\
\hline C3 - C1 & $-0,0014$ & 0,0002 & $(-0,0021 ;-0,0008)$ & 0,00 \\
\hline DIFERENÇA & TESTE DE TUKEY - PLA MASSA (g) & $(0,275 ; 0,449)$ & 0,00 \\
\hline C1 - C2 & 0,36 & 0,03 & $(-0,009 ; 0,165)$ & 0,08 \\
\hline C3 - C2 & 0,08 & 0,03 & $(-0,371 ;-0,197)$ & 0,00 \\
\hline C3 - C1 & $-0,28$ & 0,03 & $(-0,0)$ & 0,00 \\
\hline DIFERENÇA & TESTE DE TUKEY - PETG DEFORMAÇÃO NA TENSÃO MÁX. (mm/mm) \\
\hline C1 - C2 & 0,0128 & 0,0007 & $(0,0111 ; 0,0146)$ & 0,00 \\
\hline C3 - C2 & 0,0139 & 0,0007 & $(0,0121 ; 0,0156)$ & 0,00 \\
\hline C3 - C1 & 0,0010 & 0,0007 & $(-0,0008 ; 0,0028)$ & 0,32 \\
\hline DIFERENÇA & TESTE DE TUKEY - PETG MASSA (g) & $(0,055 ; 0,232)$ & 0,00 \\
\hline C1 - C2 & 0,14 & 0,03 & $(-0,115 ; 0,062)$ & 0,72 \\
\hline C3 - C2 & $-0,03$ & 0,03 & $(-0,258 ;-0,081)$ & 0,00 \\
\hline C3 - C1 & $-0,17$ & 0,03 & \\
\hline
\end{tabular}

